Please cite: Q Lu, N B Chang, J Joyce, A S Chen, D A Savic, S Djordjevic, G Fu, 2018, Exploring the potential climate change impact on urban growth in London by a cellular automata-based Markov chain model, in press. doi: 10.1016/i.compenvurbsys.2017.11.006

\title{
Exploring the Potential Flood Impact on Urban Growth in London through a Cellular Automata-based Markov Chain Model
}

\begin{abstract}
Urbanization has become a global trend under the combined influence of population growth, socioeconomic development, and globalization. Even though recent urban planning in London has been more deliberate, the relationship between climate change and urban growth in the context of economic geography are still somewhat unclear. This study relies on rainfall prediction with the aid of the Statistical DownScaling Model (SDSM), which provides the statistical foundation for future flooding potential within the urban space of London while considering major socioeconomic policies related to land use management. These SDSM findings, along with current land use policies, were included as other factors or constraints in a cellular automata-based Markov Chain model to simulate and predict land use changes in London for 2030 and 2050. Two scenarios with the inclusion and exclusion of flood impact factor, respectively, were applied to evaluate the impact of climate change on urban growth. Findings indicated: (1) mean monthly projected precipitation derived by SDSM is expected to increase for the year 2030 in London, which will affect the flooding potential and hence the area of open space; (2) urban and open space are expected to increase more than 16 and $20 \mathrm{~km}^{2}$ (in percentage of 1.51 and 1.92 compared to 2012) in 2030 and 2050, respectively, while agriculture is expected to decrease significantly due to urbanization and climate change; (3) the inclusion of potential flood impact induced from the future precipitation variability drives the development toward more open space and less urban area.

Keywords: urban growth, land use changes, flood impact, cellular automata, climate change
\end{abstract}


Please cite: Q Lu, N B Chang, J Joyce, A S Chen, D A Savic, S Djordjevic, G Fu, 2018, Exploring the potential climate change impact on urban growth in London by a cellular automata-based Markov chain model, in press. doi: 10.1016/i.compenvurbsys.2017.11.006

\section{Introduction}

As one of the megacities in Europe with the highest population density, London's unique geographic location results in an interactive relationship between its networked cities and corridors, which achieve synchronous growth. Land use changes are directly impacted by most economic, social, and environmental activities, reflecting on urban development and growth (Litman, 1995). However, in parallel with its population increase and its economic development as the financial center of Europe, the area of forest and agriculture decreased significantly between 2000 and 2006, contributing to the growth of urban and open space (Corine Land cover, 2017). As floods have been threatening the economic development of the city since the 1700s (Greater London Authority, 2002), the impacts of climate changes need to be addressed in order to shape urban planning strategies for land use changes in future scenarios. Even though recent urban planning in London has been more deliberate, the relationships between climate change and urban growth in the context of economic geography are still somewhat unclear.

Economic geography refers to location, distribution, and spatial organization involving economic activities worldwide (Clark et al., 2003). The combination of the fundamental network structure and the large size of systems consists of complex networks that could be a striking approach for growth dynamics modeling (Andersson et al., 2006). Yet incomputable networks and connections are extremely difficult to be counted or identified within the systems. Analyzing schematic structures or simple systems to represent a dynamic growth on a large scale region remains difficult to achieve. Therefore, a comprehensive and systematic approach based on different levels of factors and networks is required in order to study the complex evolving system (Barabási and Albert, 1999).

Macro-level modeling analysis involves significant portions of the internal dynamics of objects, relatives, and implications (Andersson et al., 2006). Such dynamic models can predict potential changes with global parameters, which differs from conceptual models designed simply to address one fundamental question. As one of the representative models in the urban planning regime, grid-based cellular automata $(\mathrm{CA})$ models can simulate the multiplicative growth at micro level from more detailed local activities of simple systems. Furthermore, CA models can be agglomerated in varying scales to analyze the spatial variation of a network as well as to predict potential urban evolutionary changes over a long period of time. The history of CA dates 
Please cite: Q Lu, N B Chang, J Joyce, A S Chen, D A Savic, S Djordjevic, G Fu, 2018, Exploring the potential climate change impact on urban growth in London by a cellular automata-based Markov chain model, in press. doi: 10.1016/i.compenvurbsys.2017.11.006

back to the 1940s (Von Neumann and Burks, 1966) and it was further developed by numerous studies (Batty, 2007; Clarke et al., 1997; Takeyama and Couclelis, 1997; Torrens, 2000; Xie, 1996). As extensions of CA, some approaches such as artificial neural networks (Hopfield, 1988; Yegnanarayana, 2009), logistic regression (Hu and Lo, 2007; Peduzzi et al., 1996), and Markov chain models (MC) (Guan et al., 2011; Kamusoko et al., 2009) are more related to timeseries prediction; these are general methodologies rather than only applications for simulating urban evolutionary processes.

This study relies on rainfall prediction with the aid of the Statistical DownScaling Model (SDSM) (Wilby et al., 2002), which provides the statistical foundation for future flooding potential within the urban space of London while considering major socioeconomic policies related to land use management. In this context, a CA-based MC model was applied for a spatiotemporal assessment that took advantage of the spatial values of CA models and temporal coverage of MC models simultaneously (Memarian et al., 2012). In other words, CA models can spatially simulate land use and land cover (LULC) changes in large scale based on the grid-based principle, whereas MC models are able to quantify the actual amount of changes over time periods dynamically (Moghadam and Helbich, 2013). This can be achieved due to the fact that MC models use mathematical theory to calculate the probability of changes during two certain time periods (Arsanjani et al., 2013). Therefore, CA-based MC models are ideally integrated into a modeling system to simulate LULC changes spatially based on the calculated likelihood of LULC changes over specified temporal scales mathematically. The proposed model that addresses spatiotemporal complexity specifically can thus consider long-term precipitation variability and climate change impact as a driving force to search for better urban planning strategies.

The objective of this study is therefore to simulate and predict LULC changes for 2030 and 2050 in London by using an integrated CA-based MC model regarding the interactions between climate change and urban growth from local networks and large-scale dynamics to increase the insight for future scenarios of LULC changes. Rainfall forecasting conducted by SDSM provides the statistical foundation of climate change and flood impact in 2030 and 2050. Two scenarios are developed to explore the difference between the inclusion and exclusion of climate and flood impacts. The applied software, including geographic information system (GIS) and IDRISI 
Please cite: Q Lu, N B Chang, J Joyce, A S Chen, D A Savic, S Djordjevic, G Fu, 2018, Exploring the potential climate change impact on urban growth in London by a cellular automata-based Markov chain model, in press. doi: 10.1016/i.compenvurbsys.2017.11.006

integrated in TerrSet, can collaborate and realize the goal of simulation and prediction of land use changes. With such model settings, the study seeks to analyze and answer the following three scientific questions: (1) How will rainfall change by 2030 and 2050 and what are its potential impacts on flooding within the urban space of London? (2) How would the LULC patterns of London change under the impact of climate change (i.e., rainfall variability) in 2030 and 2050 as a whole? and (3) What are the differences between the inclusion and exclusion of flood impact regarding LULC changes in 2030 and 2050 ?

\section{Study area}

London, the capital of the UK, is located in southeast England and is the largest metropolitan area in the country, as well as one of the largest urban zones in Europe. The city covers about 1,572 square kilometers (607 square miles) with a population of more than 8.67 million in 2015 . London is vulnerable to flooding from various sources, including storm surge and fluvial flood from the Thames River and surrounding tributaries as a result of heavy rainfall and overwhelmed drainage systems (Greater London Authority, 2002). Flooding can also be exacerbated by the increase in urbanized regions and the lack of green space to retain runoff.

Following World War I, green space was seen as an alternative for shifting rapid urban densification in the city's center toward suburbanization. However, the need for suburbanization threatened available green space, as policy makers sought to develop these areas in the mid-20 ${ }^{\text {th }}$ century (Rotenberg, 2008). Toward the late $20^{\text {th }}$ century, policy makers were seeking new solutions to balance urban growth while protecting green space surrounding London as much as possible (Urban Task Force, 2002). Recent practices on the policy level for the $21^{\text {st }}$ century have sought to not only protect green space surrounding the center of London but also to incorporate more green space within the city as part of sustainable drainage systems (SuDS), which can be utilized to address concerns over flood risk in London (Greater London Authority, 2015). 
Please cite: Q Lu, N B Chang, J Joyce, A S Chen, D A Savic, S Djordjevic, G Fu, 2018, Exploring the potential climate change impact on urban growth in London by a cellular automata-based Markov chain model, in press. doi: 10.1016/i.compenvurbsys.2017.11.006

\section{Data and Software}

\subsection{Data collection and pre-processing}

The data required in this study involves land use, land cover, road, Green Belt land, Central Activities zone boundary, areas for intensification points, opportunity area points, strategic industrial location points, London brownfield sites, digital elevation data, parks and gardens, and buildings (Table 1). The Greater London Authority established a new center of commercial and residential community in the Old Oak and Park Royal Development Corporation (OPDC) in 2015 (OPDC, 2017). The OPDC and the central activities zone can be integrated as one layer for the following data process. All the data require pre-processing and appropriate conversions between shapefile and raster file formats to ensure no extra error is introduced during the process.

Table 1. Applied dataset and source

\begin{tabular}{|c|c|c|c|}
\hline Data & Description & Date & Source \\
\hline Land use land cover & $100 \times 100 \mathrm{~m}$ resolution & $\begin{array}{l}2000,2006, \\
2012\end{array}$ & Corine Land Cover \\
\hline Road & Existing road & 2016 & $\begin{array}{l}\text { Ordnance Survey } \\
\text { Open Data }\end{array}$ \\
\hline Green Belt land & - & 2011 & London Datastore \\
\hline $\begin{array}{l}\text { Central Activities } \\
\text { Zone Boundary }\end{array}$ & $\begin{array}{l}\text { For strategic finance, specialist } \\
\text { retail, tourist and cultural uses and } \\
\text { activities, residential, and other } \\
\text { local functions }\end{array}$ & 2009 & London Datastore \\
\hline $\begin{array}{l}\text { Areas for } \\
\text { intensification points }\end{array}$ & $\begin{array}{l}\text { For residential, employment and } \\
\text { other uses }\end{array}$ & 2009 & London Datastore \\
\hline $\begin{array}{l}\text { Opportunity area } \\
\text { points }\end{array}$ & For new employment and housing & 2009 & London Datastore \\
\hline $\begin{array}{l}\text { Strategic industrial } \\
\text { location points }\end{array}$ & $\begin{array}{l}\text { For general business, industrial, } \\
\text { warehousing, waste management, } \\
\text { and transport sectors }\end{array}$ & 2009 & London Datastore \\
\hline OPDC & $\begin{array}{l}\text { New centre and community for } \\
\text { development }\end{array}$ & 2016 & London Datastore \\
\hline
\end{tabular}


Please cite: Q Lu, N B Chang, J Joyce, A S Chen, D A Savic, S Djordjevic, G Fu, 2018, Exploring the potential climate change impact on urban growth in London by a cellular automata-based Markov chain model, in press. doi: 10.1016/i.compenvurbsys.2017.11.006

\begin{tabular}{|l|l|l|l|}
\hline $\begin{array}{l}\text { London brownfield } \\
\text { sites }\end{array}$ & For redevelopment and reuse & 2010 & London Datastore \\
\hline $\begin{array}{l}\text { Digital elevation } \\
\text { data }\end{array}$ & $90 \times 90 m$ resolution & 2010 & $\begin{array}{l}\text { USGS SRTM 1 } \\
\text { Arc-Second Global }\end{array}$ \\
\hline Parks and gardens & Historic parks and gardens & 2016 & Historic England \\
\hline Buildings & Existing buildings & 2016 & Historic England \\
\hline Recorded flood area & Records from 1706 to 2015 & $1706-2015$ & $\begin{array}{l}\text { UK Environment } \\
\text { Agency }\end{array}$ \\
\hline
\end{tabular}

The original LULC data (2000, 2006, and 2012) include 19 to 20 land use classes, which is excessively precise but not easy for distinguishing and classification purposes, especially when land use changes. According to the data source (Corine Land cover, 2017), the data can be classified via 3 approaches: coarse classification (4 classes), moderate classification (15 classes), and sophisticated classification (44 classes). The original attribute table of the LULC data were classified following the sophisticated classification approach, but not consistently. For example, the data in 2000 do not include intertidal flats, which is presented in the 2006 and 2012 data. To better understand the land use changes and unify the classification, the initial land use classes were reclassified by combining the first and second approaches, which are finally displayed as five classes including water, urban, open space, forest, and agriculture (Figure 1). The reclassified water includes water courses, water bodies, and estuaries. Similarly, urban includes continuous urban fabric, discontinuous urban fabric, industrial or commercial units, road and rail networks and associated land, port areas, airports, mineral extraction sites, dump sites, and construction sites. Green urban areas and sport and leisure facilities are reclassified as open space. Forest includes broad-leaved forest, coniferous forest, and mixed forest. Agricultural indicates non-irrigated arable land, pastures, complex cultivation patterns, fruit trees and berry plantations, and land principally occupied by agriculture with significant areas of natural vegetation. 
Please cite: Q Lu, N B Chang, J Joyce, A S Chen, D A Savic, S Djordjevic, G Fu, 2018, Exploring the potential climate change impact on urban growth in London by a cellular automata-based Markov chain model, in press. doi: 10.1016/i.compenvurbsys.2017.11.006

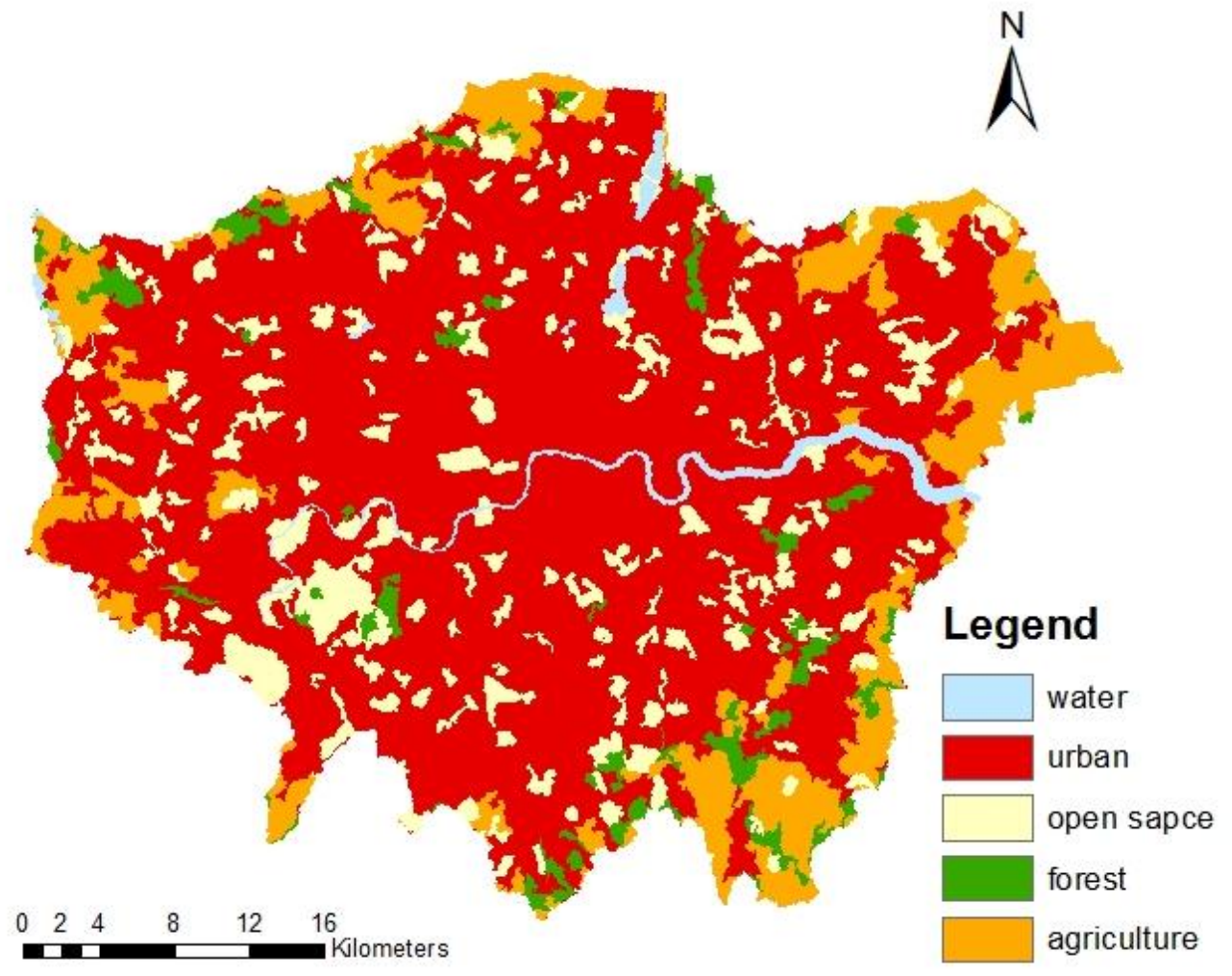

Figure 1. London land use in 2000 with re-classified land use classes (source: CLC, 2000)

The reorganized data sets (Table 2) show that the area of forest and agriculture decreased significantly between 2000 and 2006, contributing to the growth of open space. However, the difference of each land use class between 2006 and 2012 is not significant. The reason for this could be human activity-oriented policies and planning strategies which changed after 2006, according to the data analysis. The analysis of the land use data provides a basic understanding of the land use changes and the statistic foundation of the model.

Table 2. Reclassified land use class area and difference comparison (unit: hectares)

\begin{tabular}{|c|r|r|r|r|r|}
\hline land use class & \multicolumn{1}{|c|}{2000} & \multicolumn{1}{|c|}{2006} & \multicolumn{1}{c|}{2012} & $\begin{array}{c}2000-2006 \\
\text { difference }\end{array}$ & $\begin{array}{c}\text { 2006-2012 } \\
\text { difference }\end{array}$ \\
\hline water & 2736 & 2750 & 2750 & $0.51 \%$ & $0.00 \%$ \\
\hline urban & 109807 & 110670 & 110943 & $0.79 \%$ & $0.25 \%$ \\
\hline open space & 19580 & 22540 & 22526 & $15.12 \%$ & $-0.06 \%$ \\
\hline forest & 5972 & 3224 & 3215 & $-45.01 \%$ & $-0.28 \%$ \\
\hline agriculture & 21501 & 20412 & 20162 & $-5.06 \%$ & $-1.22 \%$ \\
\hline
\end{tabular}


Please cite: Q Lu, N B Chang, J Joyce, A S Chen, D A Savic, S Djordjevic, G Fu, 2018, Exploring the potential climate change impact on urban growth in London by a cellular automata-based Markov chain model, in press. doi: 10.1016/i.compenvurbsys.2017.11.006

In this study, GIS and TerrSet software were mainly used. GIS provides numerous functions for visualizing and analyzing data and has been used in comprehensive disciplines. Data preprocessing and format unification are achieved by using GIS. TerrSet, developed by Clark Labs at Clark University, is an integrated geospatial software with the ability to incorporate the IDRISI GIS analysis for monitoring and modeling purposes (Eastman, 2015). The submodule IDRISI, integrated in TerrSet for digital geospatial information analysis and display, is also adopted to quantify and predict land use changes.

\section{Methodology}

\subsection{Flood impact concern \& SDSM}

To determine the effect possible changes in climate would have on rainfall, statistical modeling techniques were used to analyze historical rainfall within the London city limits and combine data with climate modeling to project rainfall for 2030 and 2050. Increases or decreases in annual rainfall may indicate the changing likelihood of flooding. For this reason, this study aimed to determine the annual rainfall for the years 2030 and 2050. The SDSM was useful in this regard as it was adopted to determine statistical relationships between large-scale climate and local climate based on multiple linear regression techniques. These relationships were developed using observed weather data, thus these relationships can be used to obtain downscaled local information for a future time period using Global Climate Model (GCM) derived atmospheric predictors, assuming that they remain valid in the future.

For this study, daily observed rainfall records, a necessary input for SDSM, were obtained from the Meteorological Office of the UK (Met Office) via the Met Office Integrated Data Archive System (MIDAS). The records of the longest continuous period of stations with at least 20 years observations were chosen and summarized in Table 3. The period of 1961-1990 was a limiting factor for SDSM calibration and validation since two out of the three rainfall stations had a continuous record for this period in question. 
Please cite: Q Lu, N B Chang, J Joyce, A S Chen, D A Savic, S Djordjevic, G Fu, 2018, Exploring the potential climate change impact on urban growth in London by a cellular automata-based Markov chain model, in press. doi: 10.1016/i.compenvurbsys.2017.11.006

Table 3. Rainfall Stations in London with Continuous Period of Daily Rainfall Record $(20+$ yrs.)

\begin{tabular}{|c|c|c|}
\hline MIDAS Station Name & Lat/Long (Decimal Deg) & Continuous Period of Record \\
\hline $\begin{array}{c}\text { Longford-Perry Oaks Station } \\
\text { (SRC* ID: 5652) }\end{array}$ & $51.47 \mathrm{~N} / 359.5 \mathrm{~W}$ & $1961-2000$ \\
\hline $\begin{array}{c}\text { Woodford Station } \\
\text { (SRC* ID: 5533) }\end{array}$ & $51.59 \mathrm{~N} / 0.00 \mathrm{E}$ & $1961-1990$ \\
\hline $\begin{array}{c}\text { Hogsmill Valley } \\
\text { (SRC* ID: } 6570)\end{array}$ & $51.40 \mathrm{~N} / 359.7 \mathrm{~W}$ & $1961-1990$ \\
\hline
\end{tabular}

\subsubsection{SDSM predictor variables}

Selection of the best predictors is an iterative process which removes the least significant predictors until the remaining predictors are statistically significant, such that a clear relationship between predictor variables and the "predictand" or observed variable of concern can be determined. SDSM relies on both observed-derived and GCM-derived atmospheric predictor variables. Global observed predictor variables such as those from the National Center for Environmental Prediction (NCEP) (Kalnay et al., 1996) were used for SDSM calibration and validation. GCM-derived predictor variables were utilized within the "Scenario Generator" component of SDSM for future projection. GCM predictor variables covering the historical period, 1961-2001, were derived from NCEP (Wilby et al., 2002). GCM-derived atmospheric predictor variables were obtained from the Hadley Centre Coupled Model, version 3 (HADCM3) GCM A2 scenario of the Intergovernmental Panel on Climate Change Fourth Assessment Report (IPCC, 2007). HADCM3 was chosen because the Hadley Centre is one of the leading centers on climate change research in the UK. All atmospheric predictor variables were projected to the standard coordinate system $\left(2.5^{\circ}\right.$ latitude $\times 3.75^{\circ}$ longitude $)$ which were used in HADCM3, (Figure 2) covering a period from 1961 to 2099 [http://www.cccsn.ec.gc.ca/?page=pred-hadcm3] and normalized with respect to base period (1961 to 1990) averages. Normalization was required since bias or error such as large differences between observed and larger scale conditions can occur when large scale predictions do not well simulate the climate of a particular location. 
Please cite: Q Lu, N B Chang, J Joyce, A S Chen, D A Savic, S Djordjevic, G Fu, 2018, Exploring the potential climate change impact on urban growth in London by a cellular automata-based Markov chain model, in press. doi: 10.1016/i.compenvurbsys.2017.11.006

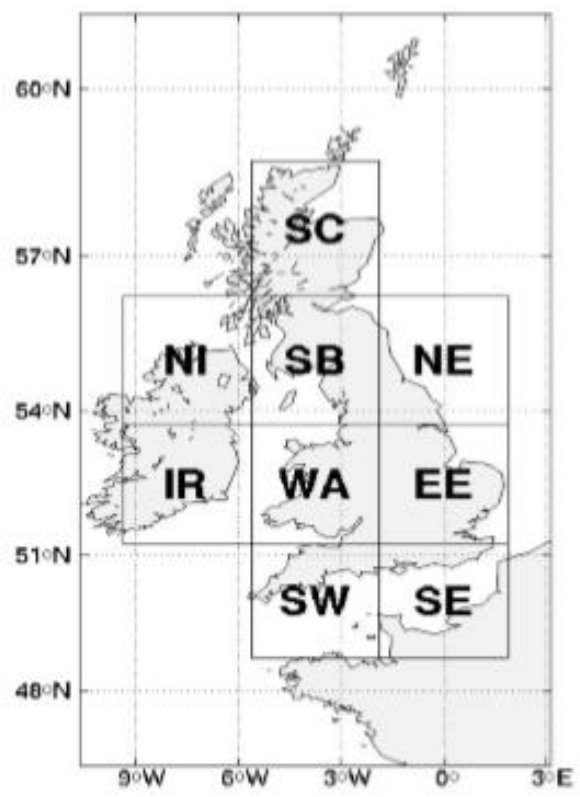

SC: Scotland; NI: Northern Ireland; SB: Scottish Borders; NE: Northeast English; IR Ireland; WA: Wales; EE: Eastern England; SW: Southwest England; SE: Southern England

Figure 2. 2.5 $^{\circ}$ latitude x 3 .75 $^{\circ}$ longitude grid system used by Hadley Centre's coupled ocean-atmosphere GCMs and NCEP. (Source: Wilby et al., 2002)

\subsubsection{SDSM-Calibration \& Validation}

Given 41 years of global NCEP daily observed-predictor variables (1961-2001), the first 14 years (1961-1975) were used for calibrating the SDSM model, while the 1976-1990 predictor variables were used to validate the model. Before calibration and validation, SDSM requires that the data are normally distributed. Daily observed rainfall over a period of record typically exhibited positively skewed behavior since the occurrences of small rainfall events were higher than the occurrences of high intensity rain events. As a result, a transformation of the data was required to obtain a normal distribution. Near-normal distribution was achieved using the log transformation of the rainfall data for both stations. The following predictors were used for SDSM model calibration: Surface airflow strength, Surface zonal velocity, Surface meridional velocity, Surface vorticity, Surface wind direction, Surface divergence, $500 \mathrm{hPa}$ airflow strength, 
Please cite: Q Lu, N B Chang, J Joyce, A S Chen, D A Savic, S Djordjevic, G Fu, 2018, Exploring the potential climate change impact on urban growth in London by a cellular automata-based Markov chain model, in press. doi: 10.1016/i.compenvurbsys.2017.11.006

$500 \mathrm{hPa}$ zonal velocity, $500 \mathrm{hPa}$ meridional velocity, $500 \mathrm{hPa}$ vorticity and $500 \mathrm{hPa}$ geopotential height. 
Please cite: Q Lu, N B Chang, J Joyce, A S Chen, D A Savic, S Djordjevic, G Fu, 2018, Exploring the potential climate change impact on urban growth in London by a cellular automata-based Markov chain model, in press. doi: 10.1016/i.compenvurbsys.2017.11.006

\subsubsection{SDSM - Future projections $(2030 \& 2050)$}

Typically, when determining changes in climate, trends are assessed via averaging over longterm time periods to remove natural variability, a process in which contributions by localized physical processes are reduced. Assessing changes in climate is typically done by observing any changes in long-term climate. A climatological baseline period of a 30-year "normal" period, as defined by the World Meteorological Organization (WMO), has been widely used. Within literature, however, climatological averages have been taken across varying time periods such as 25-yr (Pervez and Henebry, 2014) and 30-yr (Mahmood and Babel, 2012). From the given observed data, the 30-yr period of 1961-1990 is used as a baseline period for this study. The average of this 30-yr baseline period is compared to the average of the periods 2021-2049 and 2041-2070 (i.e., the 2030s and 2050s respectively). The target year of land change analysis falls within these periods for the years 2030 and 2050.

Future rainfall conditions were projected using the scenario generator in SDSM, which produces ensembles of synthetic daily weather series for future climate using the calibrated SDSM model and GCM-derived future atmospheric predictor variables. GCM-derived future atmospheric predictor variables can only be used to project future climate since the previously used NCEPobserved predictor variables are not valid for future predictions; results of projections would subsequently reveal a change in long-term average rainfall. The projection results of SDSM provide a statistical foundation of the CA-MC model for setting up the weight of climate change and flood impact driving factors in terms of predicting LULC changes in 2030 and 2050.

\subsection{CA-based MC model}

An integrated CA-based MC model was applied in this study to predict LULC changes for the city of London in the target years 2030 and 2050 with the consideration of climate change (i.e. flood impact). MC models are able to quantify the actual temporal changes between land use classes, but not spatial changes (Moghadam and Helbich, 2013). By incorporating with a MC model, a CA-based MC model can quantify and predict the spatiotemporal changes based on the transition probabilities for each local pixel (Subedi et al., 2013). The CA-based MC model was applied to simulate the stochastic process with the assumption of stationary probability distribution over time. 
Please cite: Q Lu, N B Chang, J Joyce, A S Chen, D A Savic, S Djordjevic, G Fu, 2018, Exploring the potential climate change impact on urban growth in London by a cellular automata-based Markov chain model, in press. doi: 10.1016/i.compenvurbsys.2017.11.006

In general, the model structure and flowchart are summarized in Figure 3. In phase 1, the model begins by setting up factors and constraints for each land use class, followed by applying fuzzy function for each factor and assigning Boolean values (0 or 1) for constraints. In phase 2, construction of analytical hierarchy is used for further process of fuzzification maps by using pairwise compression and assigning weights for each factor. The consistency ratio (CR) is used to measure the consistency of the weights. The Weighted factors and Boolean constraints are imported to a multi-criteria evaluation-weighted linear combination (MCE-WLC) model to generate suitability maps for all different land use types. In the meantime, the transition probability matrix is built by using MC analysis based on two sets of LULC maps representing different historical timings. The transition areas file is also an outcome of MC analysis and is generated from the Markov transition matrix with the quantity analysis of expected LULC change in the next projection period. The CA model can be run by inputting the collection of the suitability maps for all different LULC maps as well as transition rules. A 5 by 5 continuity filter needs to be applied in the CA model setting in order to impact the neighborhood cell changes. The projected LULC map in the next projection period is the outcome of the CA model, as well as the input of validation in phase 3, which compares the level of agreement between the actual observations and the projected LULC maps of the next projection period based on the Kappa statistics. If the validation result is valid, then the model is prepared for predicting LULC maps in the future. Climate change will impact future precipitation, which may be addressed by tuning the corresponding fuzzy membership value associated with the factor of distance to the flood impact area. 
Please cite: Q Lu, N B Chang, J Joyce, A S Chen, D A Savic, S Djordjevic, G Fu, 2018, Exploring the potential climate change impact on urban growth in London by a cellular automata-based Markov chain model, in press. doi: 10.1016/i.compenvurbsys.2017.11.006

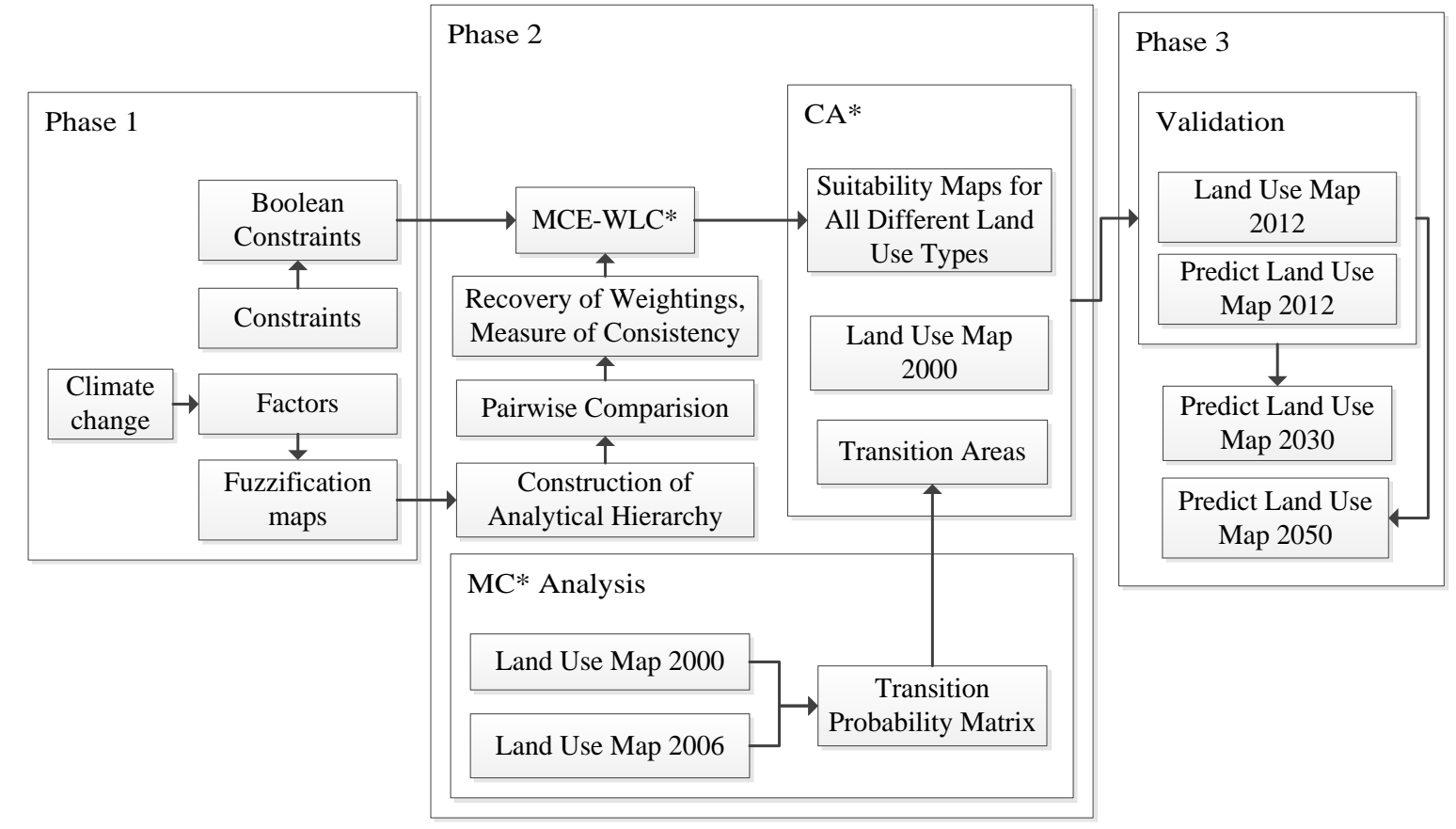

Figure 3. Study framework; *CA: cellular automata; MCE-WLC: multi-criteria evaluation-weighted linear combination; MC: Markov Chain

\subsubsection{MC}

MC models can analyze the likelihood of a random process from one stage to another via the use of transition probability matrices (López et al., 2001); such matrices have been widely applied to quantify the temporal variations between land use classes (Moghadam and Helbich, 2013). In this study, a probability matrix based on the likelihood of the land use changes between 2000 and 2006 was used for predicting the LULC map in 2012, 2030, and 2050. Assuming a constant rate of transition and setting up 2000 as the base map, the corresponding time periods to project forward from 2006 were 6 years, 24 years, and 44 years for 2012, 2030, and 2050, respectively. The mathematic formation of $\mathrm{MC}$ is shown as follow:

$$
\sum_{j=1}^{m} P_{i j}=1 \quad i=1,2 \ldots \ldots m
$$

where $P_{i j}$ represents the probability that land use changes from type $i$ in time to to type $j$ in time $t_{1}$. The matrix is built based on the combination of the probabilities that different land use 
Please cite: Q Lu, N B Chang, J Joyce, A S Chen, D A Savic, S Djordjevic, G Fu, 2018, Exploring the potential climate change impact on urban growth in London by a cellular automata-based Markov chain model, in press. doi: 10.1016/i.compenvurbsys.2017.11.006

types change to other land use types within a certain time interval. The structure of the

probability matrix P can be presented as follows (Adhikari and Southworth, 2012):

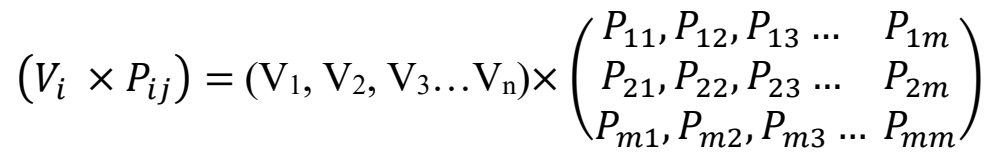

where $V_{i} \times P_{i j}$ describes the proportion of the second land use reference year; $P_{i j}$ is the transition probability of land use; $V_{i}$ is the proportion of the first land use reference year (vector); $i$ is the land use type in the first land use reference year; $j$ is the land use type in the second land use reference year; $P_{11}$ is the probability that land use type 1 in the first land use reference year changes to land use type 1 in the second land use reference year; $P_{12}$ is the probability that land use type 1 in the first land use reference year changes to land use type 2 in the second land use reference year, and so on; $m$ is the number of land use types classified in the study

In the CA-based MC model trained in TerrSet, the first outputs were the transition probability matrices. Area-based tables were constructed to present the probabilities for each land use in a convenient and straightforward way. The transition matrices indicated the probability of each land use change to other types during a certain time period. Since the 2000 LULC was identified as the base map, the transition probability matrix was generated based on the time difference between 2000 and 2006, and the 6 years interval is set up to project forward from 2006. The intervals needed to be updated additionally for predicting LULC maps in 2030 and 2050 .

\subsubsection{CA-based MC Model}

CA models can predict LULC changes based on two time intervals (Yang et al., 201), therefore they have been adopted to simulate the spatiotemporal variations of LULC in urban growth modeling (Neumann and Burks, 1966). CA models are dynamic and discrete models that use four parameters, i.e. lattice L, state space Q, neighborhood template $\delta$, and local transition function (Adamatzky, 1994) to describe the spatiotemporal changes of state in a system (Balzter et al., 1998).

$$
A=[L, Q, \delta, f]
$$


Please cite: Q Lu, N B Chang, J Joyce, A S Chen, D A Savic, S Djordjevic, G Fu, 2018, Exploring the potential climate change impact on urban growth in London by a cellular automata-based Markov chain model, in press. doi: 10.1016/i.compenvurbsys.2017.11.006

The state of each cell is defined based on $\mathrm{Q}$ and cells are also connected geometrically in different ways. The cell states of all cells vary simultaneously for each discrete time step, regulated by the neighborhood transition rules. With the collaboration of MC, cells are able to pass separately through the MC under the control of the neighborhood transition rules with a certain probability in the CA-based MC model. Spatio-temporal analysis is conducted in this model to describe the transition probabilities of each cell continuously.

\subsubsection{Factors and Constraints}

Factors and constraints play important roles in the model since they impact the formation of suitability maps for each land use class. Generally, constraints limit the specific geographic location since they are Boolean images comprising only values of 0 and 1 . Value 0 indicates that a location does not meet the developing criteria and there is no suitability of land use changes; value 1 indicates that a location meets the development criteria and has the potential to change to another land use type. The factors also indicate the suitability of a location to be developed using continuous values from 0 to 1 .

To collect and analyze policies and regulations it is important to set up factors for each land use class before modeling. Since the major land use changes happened among open space, forest, and agriculture, policies related to these land use types are the key to analyzing the changes. Specifically, open space is critical to providing flood storage responding to climate change for mitigating flood impact (Mayor of London, 2009). In this case, the change of open space depends on the dominant national policy rather than human activities or local policy variations. Another important land use class - forest, especially urban forest - also has the ability to reduce the rate and volume of stormwater runoff and eliminate flood impact (Dwyer et al., 1992). Large portions of the forest and open space are located in the Green Belt, which is defined as a mixeduse region, and prevent urban sprawl and expansion (Gant et al., 2011). In this regard, forest will be a significant factor contributing to the growth of open space, which should be reflected in the model. 
Please cite: Q Lu, N B Chang, J Joyce, A S Chen, D A Savic, S Djordjevic, G Fu, 2018, Exploring the potential climate change impact on urban growth in London by a cellular automata-based Markov chain model, in press. doi: 10.1016/i.compenvurbsys.2017.11.006

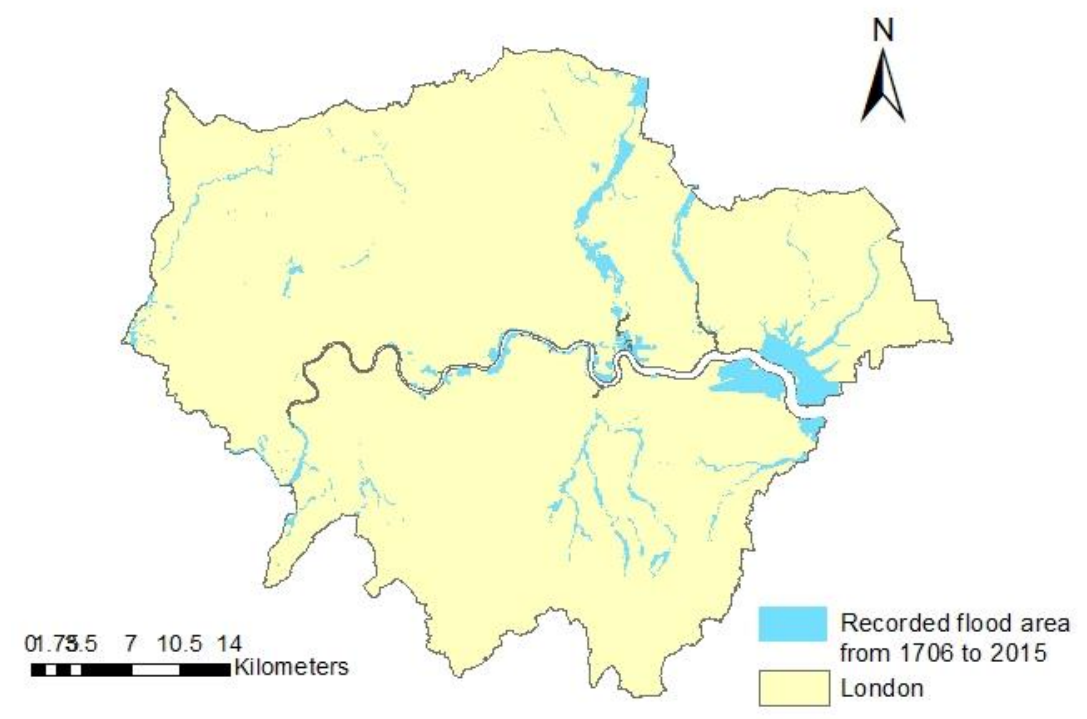

Figure 4. Recorded flood area from 1706 to 2015 in London

In recent years, climate variability's impact on flooding along the Thames River and surrounding tributaries in the future compared to the present has received a great deal of attention from the government (Greater London Authority, 2002) (Figure 4). The flood impact area has been considered as a factor of open space that supports natural ecosystem processes and offers direct and indirect benefits for flood control such as absorbing and retaining rainfall (Costanza et al., 1997). In this study, the flood impact area was considered an important factor for both urban and open space since these two land use classes consist of the majority of the total area and they are more sensitive to flood impact. Hence, the "distance to flood impact area" will be taken into account in decision analysis. From a holistic perspective, land use variations within each land use class associated with their factors are visualized in Figure 5. In general, all the driving factors need to be represented as distance to the factor in the model in order to measure the suitability variations of each factor when the distance to each factor changes. The overall factors and constraints involved in this study are summarized in Table 4. 
Please cite: Q Lu, N B Chang, J Joyce, A S Chen, D A Savic, S Djordjevic, G Fu, 2018, Exploring the potential climate change impact on urban growth in London by a cellular automata-based Markov chain model, in press. doi: 10.1016/i.compenvurbsys.2017.11.006

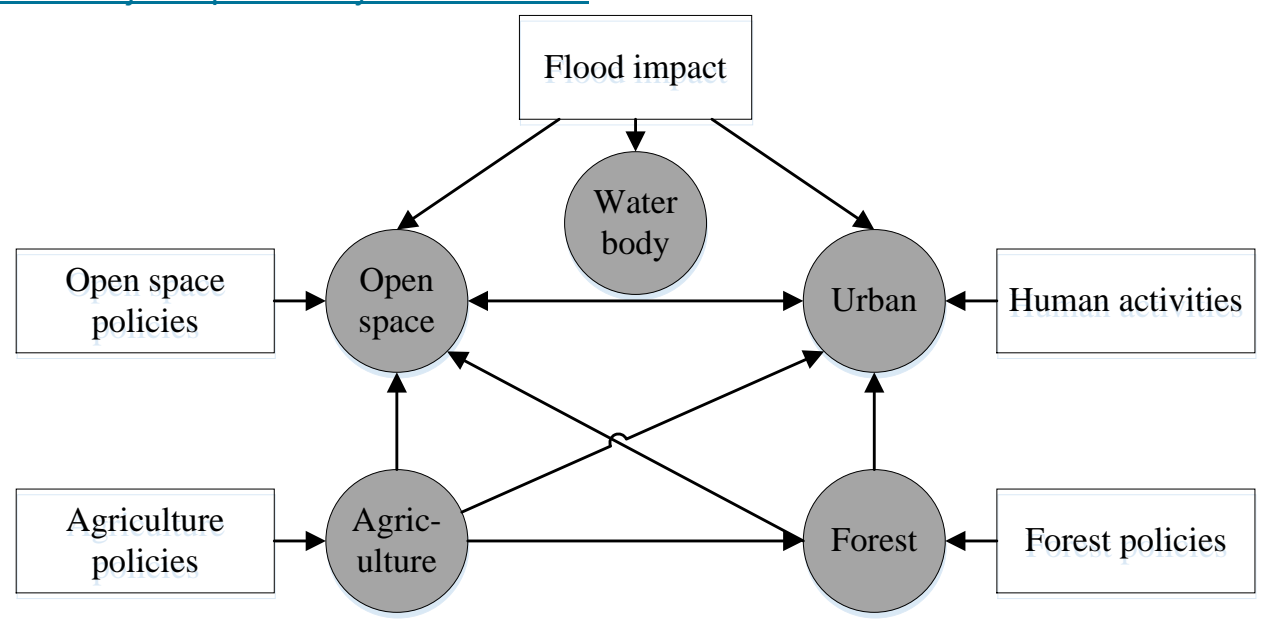

Figure 5: Land use classes' interaction relationship associated with their factors

Table 4. Factors and constraints applied in the model

\begin{tabular}{ll}
\hline Factors & Constraints \\
\hline \hline Distance from roads & Existing buildings \\
Distance to central activities zone & Water bodies \\
Distance to Slope & The Green Belt \\
Distance to industrial location & \\
Distance to intensification points & \\
Distance to opportunity area & \\
Distance to London brownfield sites & \\
Distance to parks and gardens & \\
Distance to buildings & \\
Distance to flood impact area & \\
\hline
\end{tabular}

\subsubsection{Boolean values for constraints and fuzzy membership for factors}

The constraints were assigned as a Boolean value such that the fuzzy membership functions were only applied to the corresponding factors. Each land use class was identified with the corresponding factors and constraints that will become the compositions in the fuzzy membership function. The fuzzy membership function was also incorporated as a necessity to measure the suitability of land use variations, in which the potential growth was classified as low, medium, or high for each land use class. Environmental planning and management may impact the fuzzy logic, resulting in a certain degree of flexibility of fuzzy CA. The distance 
Please cite: Q Lu, N B Chang, J Joyce, A S Chen, D A Savic, S Djordjevic, G Fu, 2018, Exploring the potential climate change impact on urban growth in London by a cellular automata-based Markov chain model, in press. doi: 10.1016/i.compenvurbsys.2017.11.006

among features (e.g. distance to road, distance to slope, distance to buildings, etc.) were calculated to create buffer zones for building the fuzzification maps. Three types of functions, linear, sigmoidal, and J-shaped, were determined based on the character of each feature to set up the fuzzy membership. Increasing or decreasing functions were also identified, as well as the control point values, which are the minimum and maximum distance values calculated previously.

\subsubsection{Analytic hierarchy process (AHP), MCE-WLC, suitability maps, and CA filters}

Given that constraints have been already assigned with values of 0 and 1, each factor defined by fuzzy membership functions was assigned a weight according to an analytical hierarchy process (AHP). AHP was conducted by weighting the impact of each factor and the interactive relationship between factors using a pairwise comparison typically conducted by expert knowledge and qualitative interview. In this study, AHP was generated based on scenario analysis, using the judgement to adjust the input. After a weight was assigned to each factor, the consistency ratio (CR) was computed to measure the reliability of the weights of factors assigned to each land use class (Ergu et al., 2011). The CR was calculated by producing a new set of ratings according to the computed weights. Ratings were generated by deriving one weight in the comparison with another weight (Xu, 2000). When the CR converged to 0 , it indicated that the assigned weights were ideal. However, the weights should be retrieved again by AHP if the CR was greater than 0.1, which was not acceptable. (Eastman, 2015). Weights were assigned based on socio-economic traditions and policies and assessed by RC.

After assigning weights to each land use class, MCE-WLC was used to generate the suitability maps for each land use class. There are three types of MCE: WLC, Boolean intersection, and ordered weighted average. In this study, MCE-WLC was used because it offers much more flexibility than the Boolean intersection and allows the criteria to be differentially weighted with full tradeoff capacity (Eastman, 2015).

Suitability maps were used to describe the suitability of land use changes of a certain land use class for each pixel. Value 0 represents no suitability, and 255 indicates the highest suitability of land use changes. All the constraints, along with Boolean values and factors that had 
Please cite: Q Lu, N B Chang, J Joyce, A S Chen, D A Savic, S Djordjevic, G Fu, 2018, Exploring the potential climate change impact on urban growth in London by a cellular automata-based Markov chain model, in press. doi: 10.1016/i.compenvurbsys.2017.11.006

continuous values between 0 and 1, were incorporated in a MCE-WLC function, generating the suitability map for each land use class. Collecting and grouping all the suitability maps as one file was required in the $\mathrm{CA}-\mathrm{MC}$ model. Before running the model, $\mathrm{CA}$ filters were identified by combining the suitability maps with MC. In this study, a standard $5 \times 5$ Boolean mask filter was used to analyze the neighborhood definition that the suitability weight of the pixels will decrease far from the existing areas and allocate preference to the neighboring suitable areas (Houet and Hubert-Moy, 2006). The relative operating characteristic (ROC) was used to assess the accuracy of the suitability maps with the fuzzy membership functions and MCE-WLC approaches. The output of the ROC estimated the area under the curve (AUC), which has been widely used for measuring the accuracy and discriminatory capacity of classification and distribution models (Beck and Shultz, 1986; Greiner et al., 2000; Jiménez - Valverde, 2012). According to Swets (1988), the ROC was defined by rating of likelihood with the binary procedure under different criteria. Usually five or more category scales with continuous quantity are set up ranging from "very unlikely" to "very likely." AUC values represent the degree of accuracy between perfect accuracy $(\mathrm{AUC}=1)$, high accuracy $(0.9<\mathrm{AUC}<1)$, moderate accuracy $(0.7<\mathrm{AUC}<0.9)$, less accuracy $(0.5<\mathrm{AUC}<0.7)$, and random locations (AUC=0.5) (Swets, 1988).

\section{Results}

\subsection{SDSM calibration and validation}

Results of calibration for the Longford, Woodford and Hogsmill Valley stations are provided in Table 5 with a monthly analysis for the period of 1961-1975. For SDSM calibration results, the R-square value represents the goodness of fit of predictor variables in explaining occurrence of observed rainfall on a monthly basis for each station. Correlation of rainfall calibration was low due to the difficulty of large scale predictors in explaining occurrence of local daily rainfall, which has been reflected in literature for certain study regions (Nguyen et al., 2005; Yang et al., 2012). Bias correction and variance inflation parameters in SDSM help improve the model after initial calibration from predictors alone. 
Please cite: Q Lu, N B Chang, J Joyce, A S Chen, D A Savic, S Djordjevic, G Fu, 2018, Exploring the potential climate change impact on urban growth in London by a cellular automata-based Markov chain model, in press. doi: 10.1016/i.compenvurbsys.2017.11.006

\section{Table 5. Correlation $\left(R^{2}\right)$ between observed rainfall and SDSM predictions at}

\section{Longford, Woodford and Hogsmill stations for the period 1961-1975}

\begin{tabular}{|c|c|c|c|}
\hline Month & Longford & Woodford & Hogsmill Valley \\
\hline January & 0.249 & 0.195 & 0.248 \\
\hline February & 0.234 & 0.217 & 0.328 \\
\hline March & 0.312 & 0.275 & 0.277 \\
\hline April & 0.208 & 0.166 & 0.285 \\
\hline May & 0.107 & 0.122 & 0.146 \\
\hline June & 0.204 & 0.269 & 0.444 \\
\hline July & 0.224 & 0.286 & 0.361 \\
\hline August & 0.114 & 0.129 & 0.186 \\
\hline September & 0.326 & 0.279 & 0.446 \\
\hline October & 0.162 & 0.177 & 0.207 \\
\hline November & 0.250 & 0.255 & 0.292 \\
\hline December & 0.233 & 0.171 & 0.168 \\
\hline
\end{tabular}

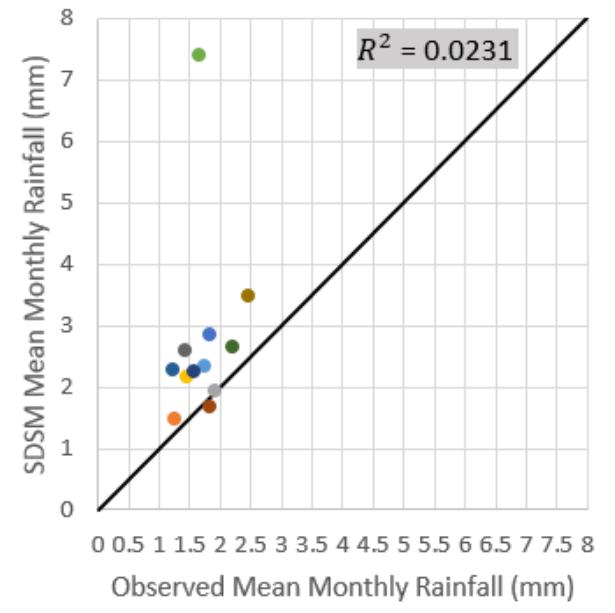

(a)

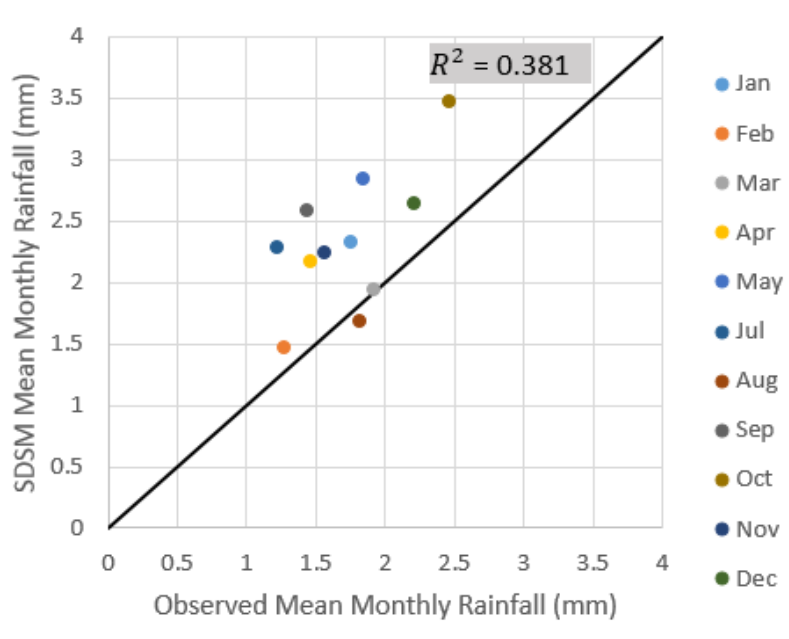

(b) 
Please cite: Q Lu, N B Chang, J Joyce, A S Chen, D A Savic, S Djordjevic, G Fu, 2018, Exploring the potential climate change impact on urban growth in London by a cellular automata-based Markov chain model, in press. doi: 10.1016/i.compenvurbsys.2017.11.006

Figure 6: Observed vs. SDSM during the validation period (1976-1990) for Longford Station with the month of June as an outlier (a) and without the month of June as an outlier (b)

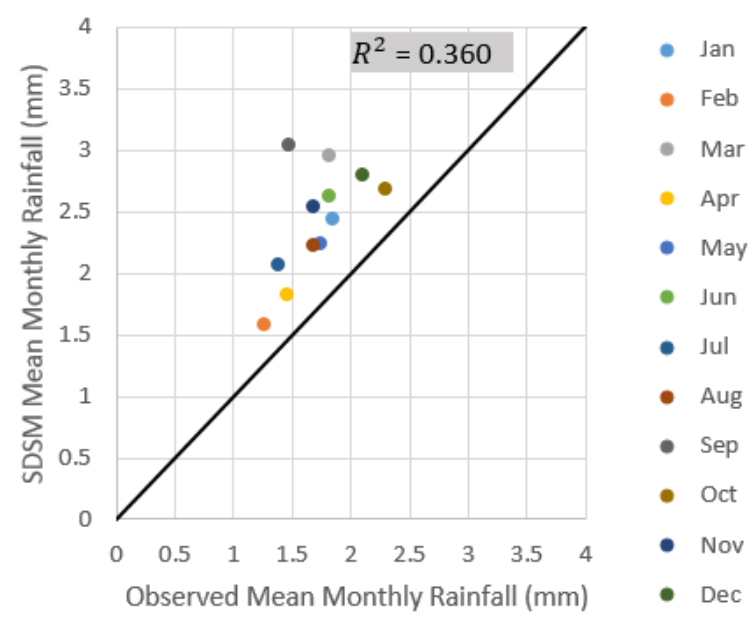

(a)

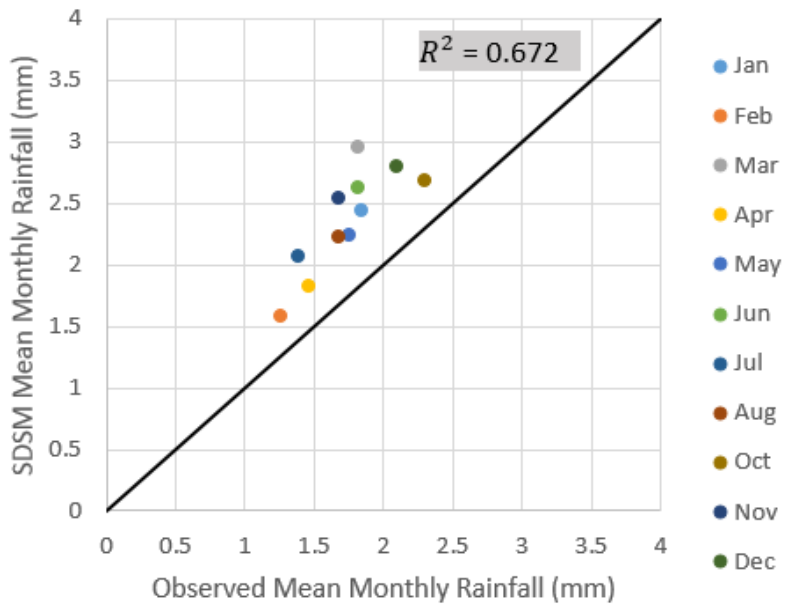

(b)

Figure 7: Observed vs. SDSM during the validation period (1976-1990) for Woodford Station with the month of September as an outlier (a) and without the month of September as an outlier (b)

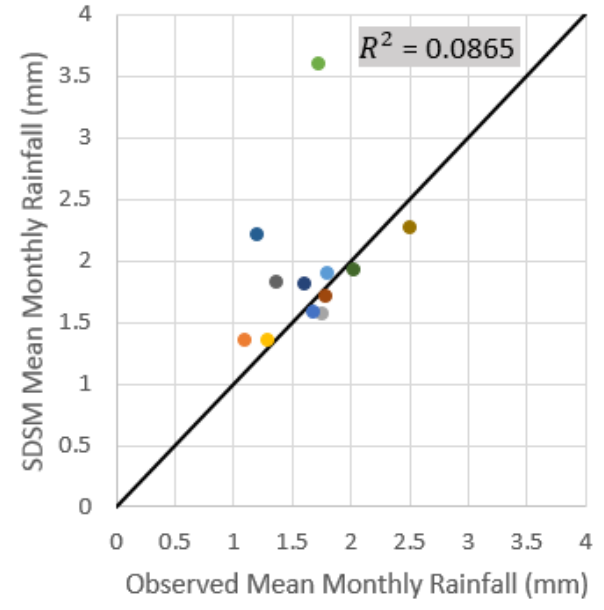

(a)

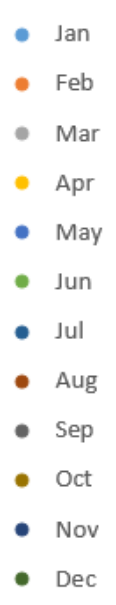

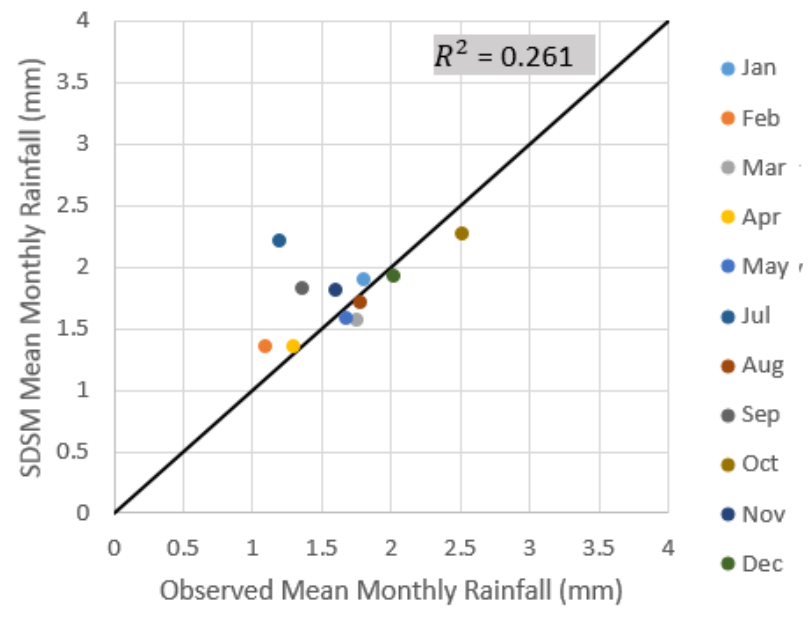

(b)

Figure 8: Observed vs. SDSM during the validation period (1976-1990) for Hogsmill Valley Station with the month of June as an outlier (a) and without the month of June as an outlier (b)

Results of validation for Longford, Woodford and Hogsmill Valley stations are provided in Figures 6, 7, and 8 respectively, on a monthly basis. Overall, SDSM slightly overestimated the 
Please cite: Q Lu, N B Chang, J Joyce, A S Chen, D A Savic, S Djordjevic, G Fu, 2018, Exploring the potential climate change impact on urban growth in London by a cellular automata-based Markov chain model, in press. doi: 10.1016/i.compenvurbsys.2017.11.006

monthly mean rainfall during the validation period (1976-1990) for the Longford station (Figure

6) with the exception of the months of February and March. A significant "bias" is evident for the month of June due to the model bias for summer rainfall. For the Woodford Station (Figure 7), which is slightly northeast of the Longford station, SDSM also slightly overestimated the monthly mean rainfall overall for the station, with greater bias evident for the month of September. Similar to the Longford station, the Hogsmill Valley station showed significant bias for the month of June (Figure 8).

\subsection{SDSM future projections}

Due to the significant bias in the SDSM model results for the Longford and Hogsmill Valley stations for the validation period, the Woodford Station was used to determine any change in long term average rainfall for the 2030s and 2050s with respect to the 30-yr baseline (19611990). Before any changes can be assessed, the performance of the HADCM3 GCM in replicating the observed averages during baseline (1961-1990) was determined (Figure 9(a)). HADCM3 performed relatively well in comparison to observed averages for the historical baseline period (1961-1990).

For the 2030s, HADCM3 A2 projected that 5 out of 12 months of the 2030s will experience noticeably increased rainfall on average with a majority of those increases occurring during the autumn months, as opposed to the summer months. For the 2050s, HADCM3 A2 projected that 3 out of 12 months will experience increased rainfall on average, indicating that the 2030s will receive more rainfall on average than the 2050s. This analysis had to be reflected in the CA-MC model to consider the climate change impact due to rainfall in the future land use scenario. 
Please cite: Q Lu, N B Chang, J Joyce, A S Chen, D A Savic, S Djordjevic, G Fu, 2018, Exploring the potential climate change impact on urban growth in London by a cellular automata-based Markov chain model, in press. doi: 10.1016/i.compenvurbsys.2017.11.006

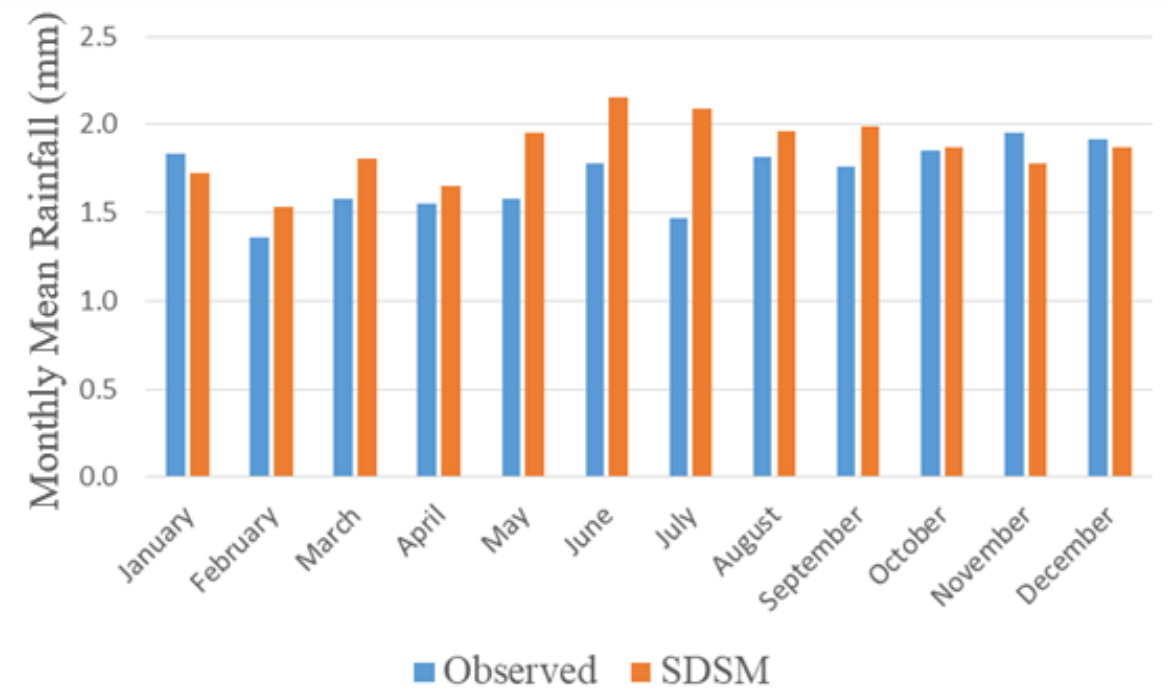

(a)

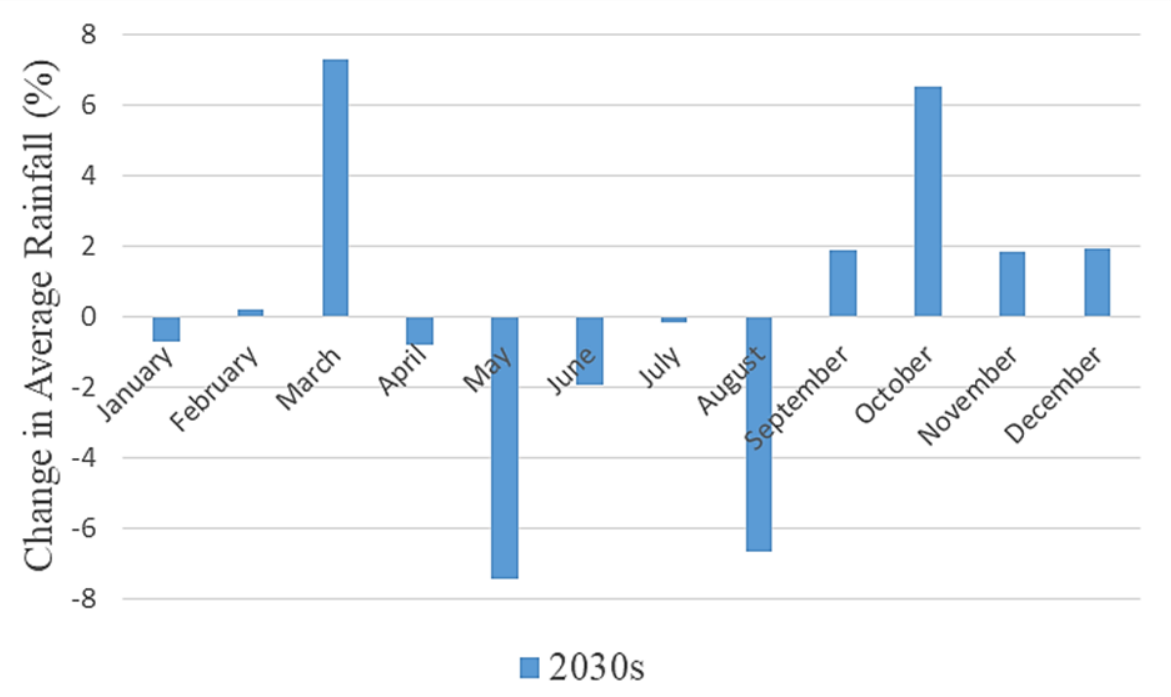

(b) 
Please cite: Q Lu, N B Chang, J Joyce, A S Chen, D A Savic, S Djordjevic, G Fu, 2018, Exploring the potential climate change impact on urban growth in London by a cellular automata-based Markov chain model, in press. doi: 10.1016/i.compenvurbsys.2017.11.006

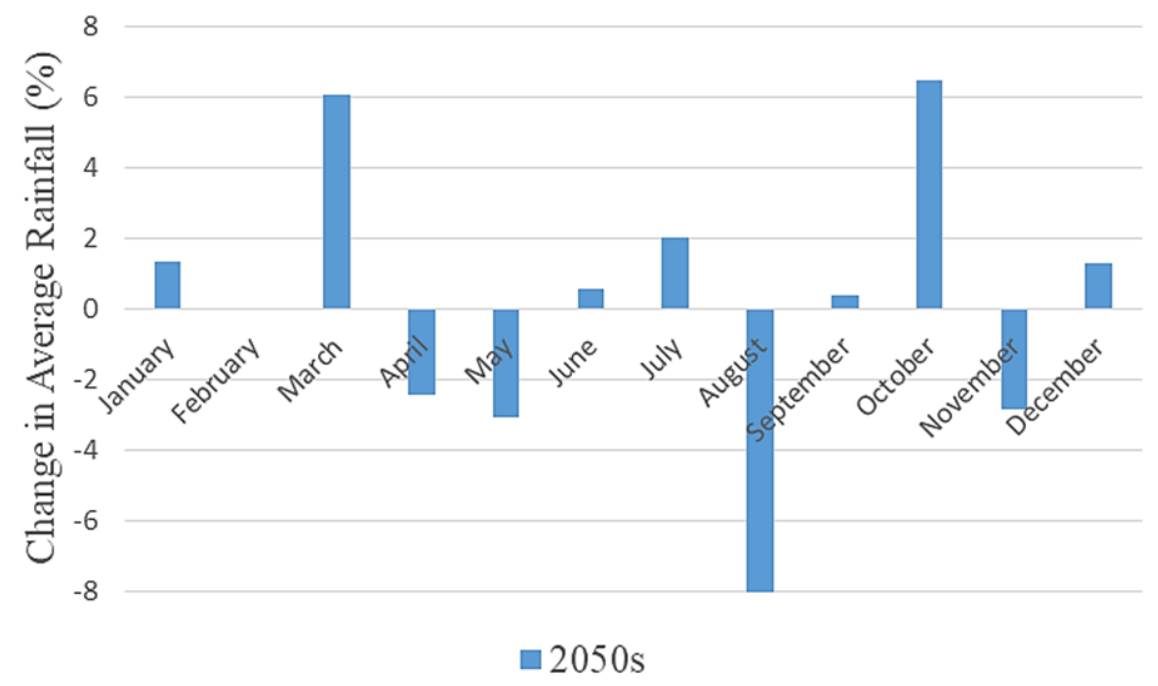

(c)

Figure 9. (a) Observed versus HADCM3 A2 GCM monthly averages during the 30-yr baseline period (1961-1990) (b) Percent average rainfall change with respect to baseline (1961-1990) during 2030s and (c) Percent average rainfall change with respect to baseline (1961-1990) during 2050s

\subsection{TerrSet Transition probability matrices}

The transition probability matrix between 2000 and 2006 for predicting the LULC map in 2012 is presented in Table 6. Based on the matrix, open space, forest, and agriculture contribute most to the growth of urban with probabilities $0.0414,0.0330$, and 0.0417 , respectively. Water body has a relatively smaller probability $(0.0095)$ to change to urban.

Table 6. Transition probability matrix between 2000 and 2006 for predicting LULC map in 2012

\begin{tabular}{lccccc}
\hline & water & urban & open space & forest & agriculture \\
\hline \hline water & 0.9653 & 0.0095 & 0.0241 & 0.0000 & 0.0011 \\
urban & 0.0003 & 0.9903 & 0.0078 & 0.0001 & 0.0014 \\
open space & 0.0006 & 0.0414 & 0.9328 & 0.0061 & 0.0192 \\
forest & 0.0017 & 0.0330 & 0.3135 & 0.4585 & 0.1934 \\
agriculture & 0.0023 & 0.0417 & 0.0690 & 0.0163 & 0.8707 \\
\hline
\end{tabular}


Please cite: Q Lu, N B Chang, J Joyce, A S Chen, D A Savic, S Djordjevic, G Fu, 2018, Exploring the potential climate change impact on urban growth in London by a cellular automata-based Markov chain model, in press. doi: 10.1016/i.compenvurbsys.2017.11.006

\subsection{TerrSet suitability maps}

Each land use class is required to set up its constraints and factors based on related policies and transition matrices. Among the land use types, urban was mostly impacted by human activities and policies. Thus, the constraints and factors were more complex and interactive. The factor weights with their functions and control points assigned for urban are shown in Table 7.

Table 7. Factors and weights for urban suitability map $(\mathrm{CR}=0.03<0.1)$

\begin{tabular}{|c|c|c|c|}
\hline Factors & Functions & Control points & Weights \\
\hline \multirow{3}{*}{$\begin{array}{l}\text { Distance from } \\
\text { roads }\end{array}$} & \multirow{3}{*}{$\begin{array}{l}\text { J-shape } \\
\text { decreasing }\end{array}$} & 0-50m highest suitability & \multirow[t]{3}{*}{0.1531} \\
\hline & & 50-1km decreasing suitability & \\
\hline & & $>1 \mathrm{~km}$ lowest suitability (equal) & \\
\hline \multirow{3}{*}{$\begin{array}{l}\text { Distance to central } \\
\text { activities zone }\end{array}$} & \multirow{3}{*}{$\begin{array}{l}\text { J-shape } \\
\text { decreasing }\end{array}$} & $0-1 \mathrm{~km}$ highest suitability & \multirow[t]{3}{*}{0.1004} \\
\hline & & $1 \mathrm{~km}-5 \mathrm{~km}$ decreasing suitability & \\
\hline & & $>2$ km lowest suitability (equal) & \\
\hline \multirow[t]{3}{*}{ Slope } & \multirow{3}{*}{$\begin{array}{l}\text { J-shape } \\
\text { decreasing }\end{array}$} & $0 \%$ highest suitability & \multirow[t]{3}{*}{0.016} \\
\hline & & $0-15 \%$ decreasing suitability & \\
\hline & & $>15 \%$ no suitability & \\
\hline \multirow{3}{*}{$\begin{array}{l}\text { Distance to } \\
\text { industrial location }\end{array}$} & \multirow{3}{*}{$\begin{array}{l}\text { J-shape } \\
\text { decreasing }\end{array}$} & 0-500m highest suitability & \multirow[t]{3}{*}{0.0606} \\
\hline & & $500 \mathrm{~m}-5 \mathrm{~km}$ decreasing suitability & \\
\hline & & $>2 \mathrm{~km}$ lowest suitability (equal) & \\
\hline \multirow{3}{*}{$\begin{array}{l}\text { Distance to } \\
\text { intensification } \\
\text { points }\end{array}$} & \multirow{3}{*}{$\begin{array}{l}\text { J-shape } \\
\text { decreasing }\end{array}$} & 0-200m highest suitability & \multirow[t]{3}{*}{0.051} \\
\hline & & 200m- $2 \mathrm{~km}$ decreasing suitability & \\
\hline & & $>2 \mathrm{~km}$ lowest suitability (equal) & \\
\hline \multirow{3}{*}{$\begin{array}{l}\text { Distance to } \\
\text { opportunity area }\end{array}$} & \multirow{3}{*}{$\begin{array}{l}\text { J-shape } \\
\text { decreasing }\end{array}$} & 0-200m highest suitability & \multirow[t]{3}{*}{0.051} \\
\hline & & 200m- $2 \mathrm{~km}$ decreasing suitability & \\
\hline & & $>2 \mathrm{~km}$ lowest suitability (equal) & \\
\hline \multirow{3}{*}{$\begin{array}{l}\text { Distance to London } \\
\text { brownfield sites }\end{array}$} & \multirow{3}{*}{$\begin{array}{l}\text { J-shape } \\
\text { decreasing }\end{array}$} & 0-100m highest suitability & \multirow[t]{3}{*}{0.112} \\
\hline & & $100 \mathrm{~m}-1 \mathrm{~km}$ decreasing suitability & \\
\hline & & $>1 \mathrm{~km}$ lowest suitability (equal) & \\
\hline \multirow{3}{*}{$\begin{array}{l}\text { Distance to parks } \\
\text { and gardens }\end{array}$} & \multirow{3}{*}{$\begin{array}{l}\text { J-shape } \\
\text { decreasing }\end{array}$} & 0-200m highest suitability & \multirow[t]{3}{*}{0.0678} \\
\hline & & $200 \mathrm{~m}-1 \mathrm{~km}$ decreasing suitability & \\
\hline & & $>1 \mathrm{~km}$ lowest suitability (equal) & \\
\hline \multirow{3}{*}{$\begin{array}{l}\text { Distance to } \\
\text { buildings }\end{array}$} & \multirow{3}{*}{$\begin{array}{l}\text { Linear } \\
\text { decreasing }\end{array}$} & $0 \%$ highest suitability & \multirow[t]{3}{*}{0.194} \\
\hline & & $0-5 \mathrm{~km}$ decreasing suitability & \\
\hline & & $>5 \mathrm{~km}$ no suitability & \\
\hline \multirow{3}{*}{$\begin{array}{l}\text { Distance to flood } \\
\text { area }\end{array}$} & \multirow{3}{*}{$\begin{array}{l}\text { J-shape } \\
\text { increasing }\end{array}$} & 0-500m lowest suitability & \multirow[t]{3}{*}{0.194} \\
\hline & & 500-1km increasing suitability & \\
\hline & & $>1 \mathrm{~km}$ highest suitability (equal) & \\
\hline
\end{tabular}


Please cite: Q Lu, N B Chang, J Joyce, A S Chen, D A Savic, S Djordjevic, G Fu, 2018, Exploring the potential climate change impact on urban growth in London by a cellular automata-based Markov chain model, in press. doi: 10.1016/i.compenvurbsys.2017.11.006

After assigning factor weights for all the land use types, the suitability maps were generated by using MCE-WLC. The suitability maps for each land use type are presented in Figure 10. The value, ranging from 0 to 1 , indicates the lowest suitability to the highest suitability. It should be noted that water area was almost constant, which was consistent with the transition matrix data as well as the observed land use map in 2006. The highest suitability for urban was still at the center of the city since it is the agglomeration of human activities. Open space basically involved parks and gardens, but the boundary between open space and forest was obscure since they may interconvert if the definitions of these terminology were vague or capricious. Forest and agriculture are essentially located in the Green Belt or near the Green Belt. Some of them were also adjacent to open space, corresponding to the suitability maps for open space as well.
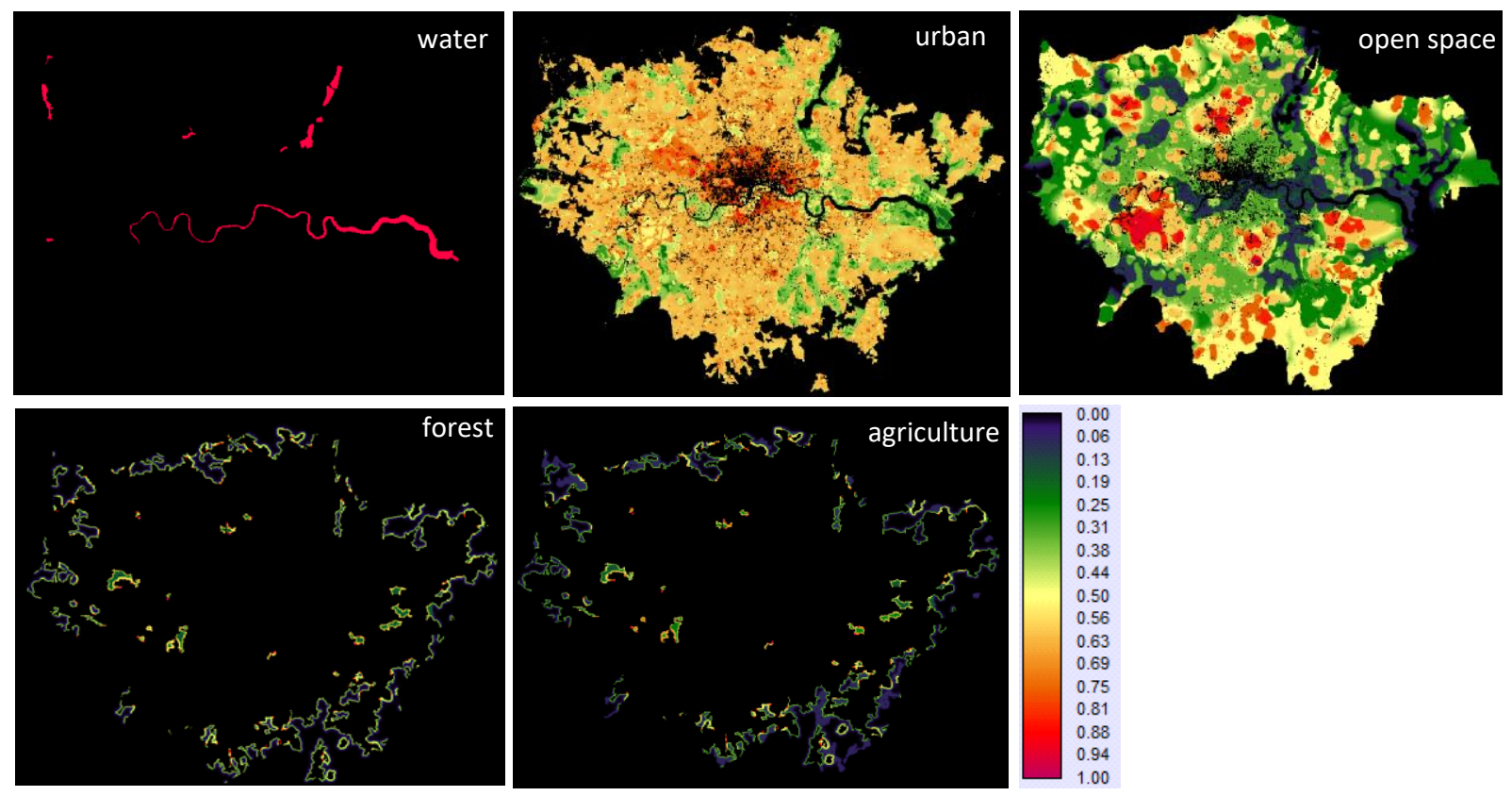

Figure 10. Suitability maps for water, urban, open space, forest, and agriculture (0 indicates no suitability, and 1 indicates the highest suitability)

To measure the accuracy of these suitability maps for each land use class, AUC was used and summarized in Table 8. Since all the AUC values are well above 0.9, the model performance of the suitability maps presents high accuracy (Swets, 1988). These high values of AUC 
Please cite: Q Lu, N B Chang, J Joyce, A S Chen, D A Savic, S Djordjevic, G Fu, 2018, Exploring the potential climate change impact on urban growth in London by a cellular automata-based Markov chain model, in press. doi: 10.1016/i.compenvurbsys.2017.11.006

approved the reliability of the previous assumptions regarding AHP and MCE-WLC. Thus, the model was ready for the LULC prediction map in 2012, which was used for validation purposes in the next step.

Table 8. AUC values for all land use classes

\begin{tabular}{|l|c|}
\hline land use class & AUC \\
\hline Water & 0.9988 \\
\hline Urban & 0.9299 \\
\hline open space & 0.9471 \\
\hline Forest & 0.9677 \\
\hline agriculture & 0.9799 \\
\hline
\end{tabular}


Please cite: Q Lu, N B Chang, J Joyce, A S Chen, D A Savic, S Djordjevic, G Fu, 2018, Exploring the potential climate change impact on urban growth in London by a cellular automata-based Markov chain model, in press. doi: 10.1016/i.compenvurbsys.2017.11.006

\subsection{TerrSet validation and prediction}

By using the VALIDATE module in TerrSet, the location agreement between the observed and projected LULC layers can be evaluated. The overall Kappa statistics (Kstandard $=0.8545$, $\mathrm{Kno}=0.9123$, Klocation $=0.8715$ ) for the validation result are well above 80 percent, indicating good agreement between the observed and projected LULC layers. After implementing validation of the model, the model was ready for predicting land use changes in 2030 and 2050. It is not easy to distinguish the land use change differences from Figure 11, but the land use area data indicate the changes and differences from 2012 to 2050 comparatively (Table 9).

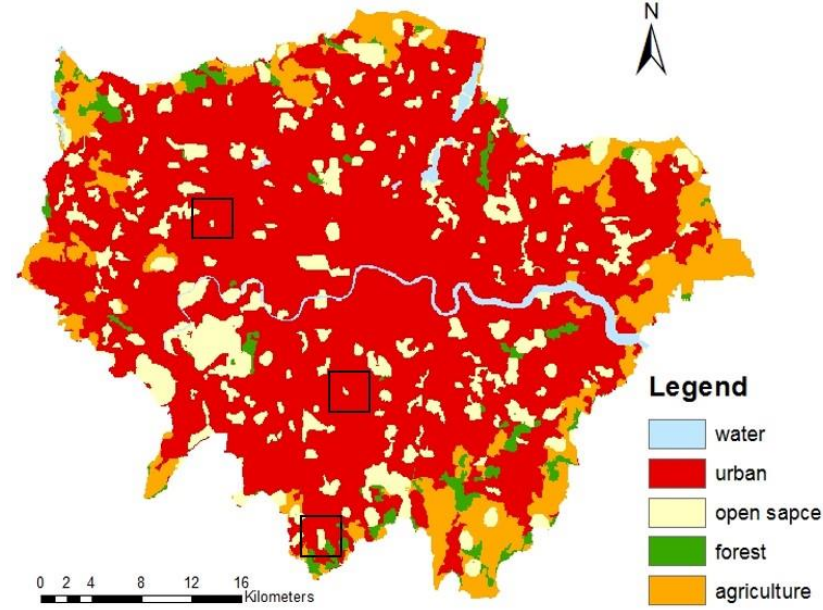

(a)

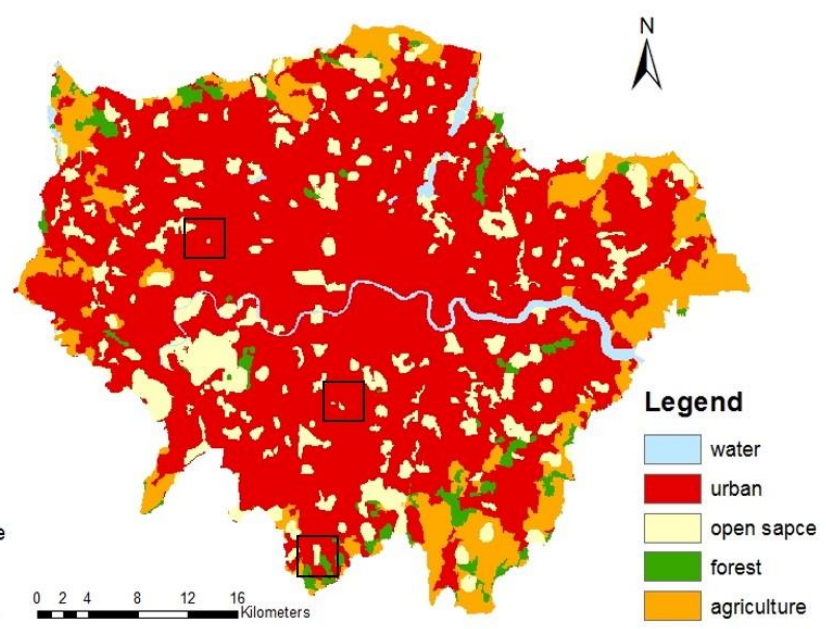

(b)

Figure 11. Predicted LULC maps in (a) 2030 and (b) 2050 with major difference in comparison highlighted by black squares

Table 9. Land use area comparison between 2012, 2030, and 2050

\begin{tabular}{|l|r|r|r|r|r|r|r|}
\hline \multirow{3}{*}{$\begin{array}{c}\text { land use } \\
\text { classes }\end{array}$} & \multicolumn{1}{|c|}{ observed } & \multicolumn{2}{|c|}{ predicted } & difference & difference & difference & difference \\
\cline { 2 - 8 } & 2012 & 2030 & 2050 & $2012-2030$ & $2012-2050$ & $2012-2030$ & $2012-2050$ \\
\cline { 2 - 8 } & \multicolumn{6}{|c|}{ unit: hectares } & \multicolumn{2}{|c|}{ in \% } \\
\hline water & 2750 & 2762 & 2770 & 12 & 20 & $0.44 \%$ & $0.73 \%$ \\
\hline urban & 110943 & 112616 & 113073 & 1673 & 2130 & $1.51 \%$ & $1.92 \%$ \\
\hline open space & 22526 & 24154 & 25204 & 1628 & 2678 & $7.23 \%$ & $11.89 \%$ \\
\hline forest & 3215 & 3672 & 3489 & 457 & 274 & $14.21 \%$ & $8.52 \%$ \\
\hline agriculture & 20162 & 16392 & 15060 & -3770 & -5102 & $-18.70 \%$ & $-25.31 \%$ \\
\hline
\end{tabular}


Please cite: Q Lu, N B Chang, J Joyce, A S Chen, D A Savic, S Djordjevic, G Fu, 2018, Exploring the potential climate change impact on urban growth in London by a cellular automata-based Markov chain model, in press. doi: 10.1016/i.compenvurbsys.2017.11.006

\section{Discussion}

Based on the prediction results, water body will expand slightly from 2012 to 2030 and 2050. Urban area is expected to expand about 16.73 and $21.30 \mathrm{~km}^{2}$ (in percentage of 1.51 and 1.92 compared to 2012) in 2030 and 2050, respectively. Meanwhile, open space is also expected to increase significantly to 16.82 and $26.78 \mathrm{~km}^{2}$ (in percentage of 7.23 and 11.89 compared to 2012) in 2030 and 2050, respectively. The increasing open space will reduce the flood impact as well as alleviate other climate change impacts. The open space protection policies (Council, 2010) and the flood impact area driving factor play important roles in protecting and supporting the expansion of open space. Although forest is also under the policy protection, the impacts of climate change and urbanization still obstruct the expansion of forest. After the significant reduction of forest from 2000 to 2006 , the policy has been changed to protect forest from being developed (Oslo, 2011). According to Oslo (2011), the European Commission adopted a green paper of forest protection in order to combat climate change. In 2030, forest will increase slightly, but decrease later because of climate change. Agriculture is expected to decrease about 37.70 and $51.02 \mathrm{~km}^{2}$ (in percentage of 18 and 25 compared to 2012) in 2030 and 2050, respectively. The reduction of agriculture area could be a result driven by policies and climate variability simultaneously, converting to the growth of urban and open space.

Comparing the scenarios via the inclusion and exclusion of flood impact area factor for both urban and open space is thus required to analyze the land use changes with respect to flood impact for the long term. The comparison between inclusion and exclusion of flood impact area scenarios can be made possible for the two target years (Table 10). When flood impact area related to urban and open space is excluded, there will be more urban area and less open space. Other changes such as water and agriculture are very slight and negligible since flood impact was not considered as a driving factor for these two land use classes. However, the use of SuDS to mitigate the flood impact area was not considered in this scenario. Inclusion of the flood impact area factor leads to a decrease of urban area and an increase of open space. Therefore, it can be concluded that the closer to the flood impact area, the higher the suitability to be converted to green space from its current land use class. 
Please cite: Q Lu, N B Chang, J Joyce, A S Chen, D A Savic, S Djordjevic, G Fu, 2018, Exploring the potential climate change impact on urban growth in London by a cellular automata-based Markov chain model, in press. doi: 10.1016/i.compenvurbsys.2017.11.006 
Please cite: Q Lu, N B Chang, J Joyce, A S Chen, D A Savic, S Djordjevic, G Fu, 2018, Exploring the potential climate change impact on urban growth in London by a cellular automata-based Markov chain model, in press. doi: 10.1016/i.compenvurbsys.2017.11.006

Table 10. The scenario comparison between the inclusion or exclusion of flood impact area for land use change prediction in 2030 and 2050

\begin{tabular}{|l|r|r|r|r|}
\hline \multirow{3}{*}{$\begin{array}{c}\text { land use } \\
\text { classes }\end{array}$} & $\begin{array}{c}|c| \\
\text { inclusion of } \\
\text { flood } \\
\text { impact area }\end{array}$ & $\begin{array}{c}\text { exclusion } \\
\text { of flood } \\
\text { impact area }\end{array}$ & $\begin{array}{c}\text { inclusion of } \\
\text { flood } \\
\text { impact area }\end{array}$ & $\begin{array}{c}\text { exclusion } \\
\text { of flood } \\
\text { impact area }\end{array}$ \\
\cline { 2 - 5 } & \multicolumn{4}{|c|}{ unit: hectares } \\
\hline water & 2762 & 2775 & 2770 & 2782 \\
\hline urban & 112616 & 112625 & 113073 & 113121 \\
\hline open space & 24154 & 24140 & 25204 & 25191 \\
\hline forest & 3672 & 3672 & 3489 & 3489 \\
\hline agriculture & 16392 & 16384 & 15060 & 15013 \\
\hline
\end{tabular}

The differences between the inclusion and exclusion of flood impact area are insignificant, which may be due to the small weight assigned to the factor. Since the socio-economic and policy-oriented driving factors are more important and contribute more to urban growth, the associated weights assigned to these factors were higher than the flood impact area factor. However, if the situation of climate change keeps deteriorating in the future, resulting in more rainfall and higher flood risk, the weight of flood impact area may increase, leading to more dramatic land use changes when this factor is included.

\section{Conclusion}

London has been suffering from flood impacts since the 1700s which threatens the development of the city in the future, especially under the projected climate variability. There is an urgent need to simulate and predict land use changes in terms of flood impact as well as other human activities with varying constraints and factors. A CA-based MC model is used in this study to simulate and predict land use changes for 2030 and 2050 in London, collaborating with the rainfall prediction via SDSM in order to provide statistical foundation for future potential flooding area. Results of SDSM show that London will experience noticeable increases in rainfall during the 2030s compared to historical long-term averages. Changes in rainfall during the 2050s, compared to historical long-term averages, are less noticeable and decrease as compared to the 2030 s. 
Please cite: Q Lu, N B Chang, J Joyce, A S Chen, D A Savic, S Djordjevic, G Fu, 2018, Exploring the potential climate change impact on urban growth in London by a cellular automata-based Markov chain model, in press. doi: 10.1016/i.compenvurbsys.2017.11.006

The results of the CA-MC model indicated that urban and open space in London are expected to increase more than 16 and $20 \mathrm{~km}^{2}$ (in percentage of 1.51 and 1.92 compared to 2012) by 2030 and 2050, respectively. Forest will slightly increase in 2030, but decrease after that due to climate change. Agriculture is expected to decrease significantly due to urbanization and climate change. The total amount of water body will slightly increase due to the increased rainfall that is expected in 2030. The comparison of two scenarios with inclusion and exclusion of flood impact factor, respectively, was developed to measure the climate change and flood impact in London. Inclusion of potential flood impact from future rainfall results in higher suitability of the development of open space, but less suitability for urban area. More support for developing open space from policy and planning views should be addressed to respond to the rigorous climate change and flood impact issues in the future.

\section{Acknowledgement}

The research is supported by the Global Innovation Initiative (British Council Gl1206), funded by the British Council and the Department for Business, Innovation and Skills.

\section{References}

Adamatzky, A.I., 1994. Identification of cellular automata. CRC Press.

Adhikari, S., Southworth, J., 2012. Simulating forest cover changes of Bannerghatta National Park based on a CA-Markov model: a remote sensing approach. Remote Sensing 4, 3215-3243. Andersson, C., Frenken, K., Hellervik, A., 2006. A complex network approach to urban growth. Environment and Planning A 38, 1941-1964.

Arsanjani, J.J., Helbich, M., Kainz, W., Boloorani, A.D., 2013. Integration of logistic regression, Markov chain and cellular automata models to simulate urban expansion. International Journal of Applied Earth Observation and Geoinformation 21, 265-275.

Balzter, H., Braun, P.W., Köhler, W., 1998. Cellular automata models for vegetation dynamics. Ecological modelling 107, 113-125.

Barabási, A.-L., Albert, R., 1999. Emergence of scaling in random networks. science 286, 509512.

Batty, M., 2007. Cities and complexity: understanding cities with cellular automata, agent-based models, and fractals. The MIT press. 
Please cite: Q Lu, N B Chang, J Joyce, A S Chen, D A Savic, S Djordjevic, G Fu, 2018, Exploring the potential climate change impact on urban growth in London by a cellular automata-based Markov chain model, in press. doi: 10.1016/i.compenvurbsys.2017.11.006

Beck, J.R., Shultz, E.K., 1986. The use of relative operating characteristic (ROC) curves in test performance evaluation. Archives of pathology \& laboratory medicine 110, 13-20.

Clark, G.L., Gertler, M.S., Feldman, M.P., 2003. The Oxford handbook of economic geography. Oxford University Press.

Clarke, K.C., Hoppen, S., Gaydos, L., 1997. A self-modifying cellular automaton model of historical urbanization in the San Francisco Bay area. Environment and planning B: Planning and design 24, 247-261.

Corine Land cover, 2017. Corine Land cover data. European Environment Agency.

Costanza, R., d'Arge, R., De Groot, R., Faber, S., Grasso, M., Hannon, B., Limburg, K., Naeem, S., O'neill, R.V., Paruelo, J., 1997. The value of the world's ecosystem services and natural capital.

Council, W.F., 2010. Open Space Strategy. Volume.

Dwyer, J.F., McPherson, E.G., Schroeder, H.W., Rowntree, R.A., 1992. Assessing the benefits and costs of the urban forest. Journal of Arboriculture 18, 227-227.

Eastman, J., 2015. TerrSet manual. Clark Labs. Clark University. Worcester, MA, USA.

Ergu, D., Kou, G., Peng, Y., Shi, Y., 2011. A simple method to improve the consistency ratio of the pair-wise comparison matrix in ANP. European Journal of Operational Research 213, 246259.

Gant, R.L., Robinson, G.M., Fazal, S., 2011. Land-use change in the 'edgelands': Policies and pressures in London's rural-urban fringe. Land Use Policy 28, 266-279.

Greater London Authority, 2002. Flooding in London: A London Assembly Scrutiny Report. London, UK.

Greater London Authority, 2015. London Sustainable Drainage Action Plan. Greater London Authority.

Greiner, M., Pfeiffer, D., Smith, R., 2000. Principles and practical application of the receiveroperating characteristic analysis for diagnostic tests. Preventive veterinary medicine 45, 23-41. Guan, D., Li, H., Inohae, T., Su, W., Nagaie, T., Hokao, K., 2011. Modeling urban land use change by the integration of cellular automaton and Markov model. Ecological Modelling 222, 3761-3772.

Hopfield, J.J., 1988. Artificial neural networks. IEEE Circuits and Devices Magazine 4, 3-10. 
Please cite: Q Lu, N B Chang, J Joyce, A S Chen, D A Savic, S Djordjevic, G Fu, 2018, Exploring the potential climate change impact on urban growth in London by a cellular automata-based Markov chain model, in press. doi: 10.1016/i.compenvurbsys.2017.11.006

Houet, T., Hubert-Moy, L., 2006. Modelling and projecting land-use and land-cover changes with a cellular automaton in considering landscape trajectories: an improvement for simulation of plausible future states. EARSeL eProceedings 5, 63-76.

Hu, Z., Lo, C., 2007. Modeling urban growth in Atlanta using logistic regression. Computers, Environment and Urban Systems 31, 667-688.

Jiménez - Valverde, A., 2012. Insights into the area under the receiver operating characteristic curve (AUC) as a discrimination measure in species distribution modelling. Global Ecology and Biogeography 21, 498-507.

Kalnay, E., Kanamitsu, M., Kistler, R., Collins, W., Deaven, D., Gandin, L., Iredell, M., Saha, S., White, G., Woollen, J., 1996. The NCEP/NCAR 40-year reanalysis project. Bulletin of the American meteorological Society 77, 437-471.

Kamusoko, C., Aniya, M., Adi, B., Manjoro, M., 2009. Rural sustainability under threat in Zimbabwe-simulation of future land use/cover changes in the Bindura district based on the Markov-cellular automata model. Applied Geography 29, 435-447.

Litman, T., 1995. Land use impact costs of transportation. World Transport Policy and Practice 1, 9-16.

López, G.G.I., Hermanns, H., Katoen, J.-P., 2001. Beyond memoryless distributions: Model checking semi-Markov chains, Process Algebra and Probabilistic Methods. Performance Modelling and Verification. Springer, pp. 57-70.

Mahmood, R. and Babel, M.S., 2013. Evaluation of SDSM developed by annual and monthly sub-models for downscaling temperature and precipitation in the Jhelum basin, Pakistan and India. Theoretical and Applied Climatology,113, 1434-4483.

Mayor of London, 2009. Open space strategies: Best practice guidance.

https://www.designcouncil.org.uk/sites/default/files/asset/document/open-space-strategies.pdf.

Memarian, H., Balasundram, S.K., Talib, J.B., Sung, C.T.B., Sood, A.M., Abbaspour, K., 2012. Validation of CA-Markov for simulation of land use and cover change in the Langat Basin, Malaysia.

Moghadam, H.S., Helbich, M., 2013. Spatiotemporal urbanization processes in the megacity of Mumbai, India: A Markov chains-cellular automata urban growth model. Applied Geography 40, $140-149$. 
Please cite: Q Lu, N B Chang, J Joyce, A S Chen, D A Savic, S Djordjevic, G Fu, 2018, Exploring the potential climate change impact on urban growth in London by a cellular automata-based Markov chain model, in press. doi: 10.1016/i.compenvurbsys.2017.11.006

Nguyen, V., Nguyen, T., Gachon, P., Lee, J., Lam, K., 2005. An evaluation of statistical

downscaling methods for simulating daily precipitation and extreme temperature series at a local site, Environmental hydraulics and sustainable water management. Volume 1, environmental hydraulics: Volume 2, sustainable water management in the Asia-Pacific region. Proceedings of the 4th International Symposium on Environmental Hydraulics and the 14th Congress of Asia and Pacific Division, International Association of Hydraulic Engineering and Research, Hong Kong, 15-18 December 2004. Taylor \& Francis, pp. 1911-1916.

OPDC, 2017. Old oak and park royal devlelopment corporation. Mayor of London, retrieved from https://www.london.gov.uk/about-us/organisations-we-work/old-oak-and-park-royaldevelopment-corporation-opdc.

Oslo, F.E.L.U., 2011. State of Europe's Forests, 2011: Status \& Trends in Sustainable Forest Management in Europe. Ministerial Conference on the Protection of Forests in Europe, Forest Europe, Liaison Unit Oslo.

Peduzzi, P., Concato, J., Kemper, E., Holford, T.R., Feinstein, A.R., 1996. A simulation study of the number of events per variable in logistic regression analysis. Journal of clinical epidemiology 49, 1373-1379.

Pervez, M.S. and Henebry, G.M., 2014. Projections of the Ganges-Brahmaputra precipitationDownscaled from GCM predictors, Journal of Hydrology,517, 120-134, ISSN 0022-1694, http://dx.doi.org/10.1016/j.jhydrol.2014.05.016.

Rotenberg, R., 2008. The European City and Green Space: London, Stockholm, Helsinki and St. Petersburg, 1850-2000-Edited by Peter Clark. International Journal of Urban and Regional Research 32, 523-525.

Subedi, P., Subedi, K., Thapa, B., 2013. Application of a hybrid cellular automaton-Markov (CA-Markov) Model in land-use change prediction: a case study of saddle creek drainage Basin, Florida. Applied Ecology and Environmental Sciences 1, 126-132.

Swets, J.A., 1988. Measuring the accuracy of diagnostic systems. Science 240, 1285-1293.

Takeyama, M., Couclelis, H., 1997. Map dynamics: integrating cellular automata and GIS through Geo-Algebra. International Journal of Geographical Information Science 11, 73-91. Torrens, P.M., 2000. How cellular models of urban systems work (1. Theory). 
Please cite: Q Lu, N B Chang, J Joyce, A S Chen, D A Savic, S Djordjevic, G Fu, 2018, Exploring the potential climate change impact on urban growth in London by a cellular automata-based Markov chain model, in press. doi: 10.1016/i.compenvurbsys.2017.11.006

Urban Task Force, 2002. Towards an urban renaissance: final report of the urban task force

chaired by Lord Rogers of Riverside, The Department of the Environment. Transport, and Regions (DoE), London.

Von Neumann, J., Burks, A.W., 1966. Theory of self-reproducing automata. IEEE Transactions on Neural Networks 5, 3-14.

Wilby, R.L., Dawson, C.W., Barrow, E.M., 2002. SDSM-a decision support tool for the assessment of regional climate change impacts. Environmental Modelling \& Software 17, 145157.

Xie, Y., 1996. A generalized model for cellular urban dynamics. Geographical Analysis 28, 350373.

$\mathrm{Xu}, \mathrm{Z}$., 2000. On consistency of the weighted geometric mean complex judgement matrix in AHP. European Journal of Operational Research 126, 683-687.

Yang, T., Li, H., Wang, W., Xu, C.Y., Yu, Z., 2012. Statistical downscaling of extreme daily precipitation, evaporation, and temperature and construction of future scenarios. Hydrological Processes 26, 3510-3523.

Yegnanarayana, B., 2009. Artificial neural networks. PHI Learning Pvt. Ltd. 